\title{
RESPONSABILIDAD CIVIL \\ POR DAÑOS DERIVADOS \\ DE FENÓMENOS NATURALES. \\ UNA REVISIÓN JURISPRUDENCIAL
}

\section{CIVIL LIABILITY FOR DAMAGES ARISING FROM NATURAL PHENOMENA. A JURISPRUDENCE REVIEW}

\author{
Lilian C. San Martín Neira*
}

\section{RESUMEN}

Este artículo presenta una revisión de la jurisprudencia chilena relativa a demandas de responsabilidad civil por daños derivados de fenómenos naturales. Da cuenta de una evolución en la materia, en virtud de la cual se transitó de un periodo en que los daños ocasionados por fenómenos naturales en estricto sentido no daban lugar demandas de responsabilidad a un periodo en que abundan las demandas asociadas a este tipo de fenómenos. Todo lo cual es producto de una nueva concepción de los fenómenos naturales, que ya no son vistos como fatalidades, sino como amenazas que pueden ser conjuradas con la correcta gestión del riesgo.

Palabras clave: desastres naturales; responsabilidad civil derivada de fenómenos naturales; caso fortuito; deber de gestión del riesgo.

\section{AbStract}

This article presents a review of the Chilean jurisprudence concerning claims for civil liability for damages arising from natural phenomena. It reveals an evolution in the matter. The situation changed from a period in which damage caused by natural phenomena in strict sense did not give

* Profesora de Derecho Civil, Universidad Alberto Hurtado. Este artículo forma parte del proyecto Fondecyt n. ${ }^{\circ} 1170686$, del que su autora es investigadora responsable. Dirección postal: Cienfuegos 41, Santiago, Región Metropolitana, Chile. Correo electrónico: isanmar@uahurtado.cl

Recepción: 2020-10-02; aceptación: 2021-01-11. 
rise to demands for liability to a period in which the claims associated with such phenomena abound. All of which is the product of a new conception of natural phenomena, which are no longer seen as fatality, but as a hazard that could be avoid with a proper risk management.

Keywords: Natural disasters; civil liability arising from natural phenomena; act of God; duty of risk management.

\section{INTRODUCCIÓN}

Se habla de fenómenos naturales extremos para referirse a aquellos eventos de la naturaleza con alto potencial destructivo y que, por tanto, constituyen amenazas de daños para las personas o comunidades expuestas a ellos. Entre otros, son fenómenos de este tipo: las lluvias torrenciales, los deslizamientos de tierra, los huracanes, las erupciones volcánicas, los terremotos y maremotos o tsunamis. Así descritos, salta a la vista que la potencialidad dañina no depende tanto de la magnitud del evento, cuanto del nivel de exposición de la población al mismo; de ahí que la literatura especializada se refiera a las versiones más drásticas de estos fenómenos con el nombre de desastres socionaturales ${ }^{1}$.

Por otro lado, atendido el origen natural de estos sucesos, históricamente ellos han sido considerados infortunios o fatalidades que deben ser soportados por el hecho de vivir en el lugar afectado. En lo que atañe a este trabajo, ello implicaba su asociación automática con la institución del caso fortuito o fuerza mayor y, por consiguiente, con la aplicación directa de la máxima casum sentit dominus, lo que derivaba en la casi total ausencia de demandas de responsabilidad civil extracontractual (e, incluso, contractual) a raíz de los daños provocados por este tipo de fenómenos, pero este panorama ha cambiado.

El avance de la ciencia y la tecnología, así como el perfeccionamiento de los estudios científicos y sociales relativos a este tipo de fenómenos han

1 "El riesgo natural es la posibilidad de que un territorio y la sociedad que lo habita pueda verse afectado por un fenómeno natural extraordinario. La catástrofe es el efecto perturbador que provoca sobre un territorio un episodio natural extraordinario y que a menudo supone la pérdida de vidas humanas. Si las consecuencias de dicho episodio natural alcanzan una magnitud tal que ese territorio necesita ayuda externa en alto grado se habla de desastre, concepto que alude al deterioro que sufre la economía de la región y al drama social provocado por la pérdida de numerosas vidas”. Cfr. Olcina (2006), p. 71. La literatura más reciente, sin embargo, habla de desastres "socionaturales" "desplazando la atención desde las amenazas naturales hacia la vulnerabilidad social o susceptibilidad de la población a sufrir daños en función de su exposición, localización geográfica sobre sitios amenazantes o pertenencia a grupos sensibles". Cfr. Romero y VidAL (2014), p. 24. 
llevado a que se tome conciencia de que, si bien el fenómeno natural no puede ser atribuido a ninguna persona, no ocurre lo mismo con el daño, pues este puede ser el resultado de la concomitancia del fenómeno natural con la conducta negligente, por acción u omisión, de un determinado sujeto, quien resultará obligado a pagar la correspondiente indemnización. Esta idea es en particular interesante cuando quien sufre el daño carece de todo vínculo obligacional previo con el sujeto sindicado como causante del mismo, pues, en muchos casos, la configuración del deber de cuidado dependerá de la posibilidad de identificar la norma que imponía al demandado el deber de evitar el daño a través de la gestión del riesgo natural.

En atención a esas consideraciones, este texto se ocupa, en primer lugar, de demostrar la evolución que ha presentado la percepción social de los fenómenos naturales y la respuesta a los mismos. En segundo lugar, a partir de las ideas ya asentadas, se encarga de analizar la repercusión que esa evolución ha tenido en la responsabilidad civil. Con este último propósito, se realiza un análisis exegético de la jurisprudencia chilena relativa a demandas de responsabilidad civil (fundamentalmente extracontractual) por daños ocasionados por fenómenos naturales. En particular, el texto se centra en aquellos fenómenos de origen estrictamente natural, es decir, que se producen de manera independiente de la voluntad o la intervención humana, dejando fuera aquellos de carácter antrópico, es decir, que solo se producen gracias a la intervención del hombre 2 .

Para llevar a cabo el estudio, se consideró un arco de tiempo que va desde el año 2000 hasta 2019, analizando principalmente sentencias de la Corte Suprema disponibles en bases de datos especializadas, en específico Thomson Reuters y VLex ${ }^{3}$. Los criterios de búsqueda empleados fueron la

${ }^{2}$ Los ejemplos más típicos de este tipo de fenómenos son los incendios, pues su generación espontánea constituye una situación excepcional. Justamente, a raíz de esa consideración, este tipo de eventos ha dado desde antiguo lugar a responsabilidad civil. Como se dijo, este texto alude a los fenómenos naturales en sentido estricto, de modo que no contempla un análisis de la literatura, ni de la jurisprudencia relativa a los incendios de ningún tipo.

${ }^{3}$ En la identificación de los fallos relativos a demandas entre privados fue de gran ayuda la tesis de grado llevada a cabo bajo mi dirección por la estudiante Mikaela Kehsler, véase KEHSLER (2018). Mientras que en lo relativo a las demandas contra el fisco u otras entidades estatales, se utilizó también la información proporcionada como respuesta a un requerimiento de transparencia realizado por la ayudante Nicole Rojas ante el Consejo de Defensa del Estado. Se trata de la solicitud de información pública n. ${ }^{\circ}$ AX001T0000511, de fecha 12 de junio de 2018, mediante la cual se solicitó información relativa a todas las demandas fundadas en desastres naturales y los principales fenómenos naturales que afectan a Chile (incluidos los incendios forestales) dirigidas en contra del Estado o de cualquier organismo público; la solicitud fue respondida mediante ordinario 00225, de 
expresión "desastre natural" y las voces correspondientes a los principales tipos de desastres que afectan a Chile: inundación, terremoto, tsunami o maremoto, aluvión, alud o deslizamiento de tierra, erupción volcánica y marejadas. Siempre que ello fue posible, las sentencias ubicadas en la red fueron cotejadas directamente con el portal de autoconsulta del Poder Judicial, para tener acceso a los fallos de primera y segunda instancia ${ }^{4}$. La búsqueda arrojó un universo aproximado de doscientas sentencias de la Corte Suprema, entre las cuales se excluyeron aquellas en que se invocaba la responsabilidad ambiental fundada en la Ley n. ${ }^{\circ} 19300$, así como aquellas relativas a incendios forestales y, en general, las que no presentaban cuestiones relevantes para efectos de este estudio. De esta manera, la muestra se acotó a las sesenta y cuatro sentencias que se individualizan al final del texto. La elección del periodo obedece a dos factores determinantes. En primer lugar, el hecho de que a partir de la década del noventa del siglo pasado es posible observar un notorio aumento en las demandas de responsabilidad civil en general en Chile, juicios que en su mayoría fueron fallados por la Corte Suprema en los primeros años de la década de 2000 y son estas las sentencias que importan en esta sede. En segundo lugar, el hecho de que, luego del terremoto y tsunami del $27 \mathrm{~F}$ proliferaron las demandas de responsabilidad civil por este tipo de daños, sobre todo en contra del Estado, lo que ha dado lugar a una abundante jurisprudencia sobre la materia.

En lo sucesivo, el trabajo se divide en siete partes correspondientes respectivamente a:

I) Chile país de catástrofes naturales: el paso desde la reacción a la emergencia a la gestión del riesgo;

II) surgimiento y consolidación de la responsabilidad por daños asociados a fenómenos naturales;

III) los fenómenos naturales como condiciones necesarias del daño: la configuración de la responsabilidad por errónea gestión del riesgo en la jurisprudencia chilena;

IV) la incertidumbre causal asociada a los daños derivados de fenómenos naturales;

V) la extensión de la indemnización: ausencia de fraccionamiento de la indemnización fundada en el aporte causal del fenómeno natural;

fecha 3 de julio de 2018. En su respuesta el Consejo entregó exclusivamente los datos relativos a la primera instancia de todas las causas, doscientos ochenta en total. De modo que la búsqueda definitiva se realizó igualmente en las bases de datos jurisprudenciales.

${ }^{4}$ En algunos casos, en especial las más antiguas, el portal del Poder Judicial no cuenta con información completa de los juicios. 
VI) fenómenos naturales y función preventiva de la responsabilidad civil. La posibilidad de ejercer la acción de daño contingente para prevenir que los fenómenos naturales se transformen en daños;

VII) un cuerpo de conclusiones.

\section{Chile PAÍS de CATÁSTROFES NATURALEs:}

EL PASO DESDE LA REACCIÓN A LA EMERGENCIA A LA GESTIÓN DEL RIESGO

Tal y como indica el considerando 1 del DS 1512 del Ministerio del Interior,

"Chile es un país expuesto de manera permanente a amenazas de origen natural como antrópicas, entre las que destacan los terremotos, tsunamis, erupciones volcánicas, inundaciones, incendios forestales, entre otras" 5 .

La ocurrencia de fenómenos naturales extremos y sus consecuentes daños constituyen una constante en la historia chilena pre y poscolombina. De ello dan cuenta la mitología y leyendas de los pueblos ancestrales ${ }^{6}$, así como los libros que narran la historia de Chile desde su formación como nación ${ }^{7}$. Por su parte, los estudios más recientes con que se cuenta en la materia han concluido que se registran al menos setenta desastres de origen geológico entre 1980 y $2017^{8}$ y una cantidad equivalente de desastres climáticos e hidrometeorológicos ${ }^{9}$. Según los expertos, este elevado número lo coloca entre los países más afectados a raíz de este género de eventos y también uno de los más expuestos a riesgos futuros ${ }^{10}$. Además,

${ }^{5}$ Cfr. considerando 1 del DS 1512 del Ministerio del Interior.

${ }^{6}$ Como es el caso de los seres mitológicos Cai Cai y Treng Treng, serpientes que gobiernan las fuerzas de la naturaleza provocando con su enojo terremotos, erupciones volcánicas, maremotos e inundaciones, así como la leyenda de la princesa Licarayen, que narra cómo el pueblo mapuche calmó la furia de un dios alojado dentro de un volcán con el sacrificio de una doncella.

${ }^{7}$ En su conocido Compendio de la historia geográfica y natural del reino de Chile, el abate Juan Ignacio Molina describe las principales erupciones volcánicas y terremotos que afectaron a Chile durante la Colonia hasta la publicación de su libro en la segunda mitad del siglo XVIII, destacando, también, cómo el pueblo chileno se había preparado para enfrentar este tipo de fenómenos, especialmente los terremotos. Véase Molina (1788), p. 29 y ss.

${ }^{8}$ Véase Sernageomin (2017).

${ }^{9}$ Henríquez et al. (2016), pp. 27-44.

${ }^{10}$ Un estudio alemán publicado en 2018 coloca a Chile como uno de los países con mayor riesgo de terremoto. Véase AA.VV. (2018). 
como consecuencia del cambio climático y la configuración geológica del país, el escenario antes descrito está destinado a repetirse e, incluso, a incrementarse ${ }^{11}$.

La diversidad y la frecuencia con que acontecen tales fenómenos han determinado un acostumbramiento social a este tipo de sucesos ${ }^{12}$. En sentido figurado, es posible afirmar que este acostumbramiento forma parte del ADN chileno. En efecto, según la literatura especializada, los desastres naturales, en especial los terremotos, han contribuido a forjar el carácter chileno ${ }^{13}$, transformándolo en un pueblo resiliente y solidario, pero también desapegado de sus afectos ${ }^{14}$.

Esa forma de advertir la fatalidad de los fenómenos de la naturaleza y sus consecuencias se encuentra también en el ámbito jurídico, que es (o debiera ser) el reflejo de la sociedad que está llamada a regir. En lo que aquí importa, ello determinó que durante buena parte de la historia de Chile la ocurrencia de desastres naturales no diera lugar a demandas sociales, ni menos de responsabilidad civil ${ }^{15}$. Naturalmente, el Estado reaccionaba frente a la ocurrencia de estos fenómenos, otorgando "ayuda" a la población e implementando medidas de reconstrucción. Así, a modo de ejemplo, cabe mencionar que a causa del terremoto de Chillán de 1939 surge lo que ahora conocemos como la Corfo ${ }^{16}$ cuya misión era

${ }^{11}$ ViCUÑa (2019), p. 284 y ss. La literatura especializada es enfática al afirmar una directa vinculación entre el cambio climático y el aumento de fenómenos naturales extremos, especialmente de fenómenos climatológicos, como huracanes, sequías, diluvios, etc. Véase Hassol et al. (2016); SANTiAgo-Lastra et al. (2008) y Ríos et al. (2013).

${ }^{12}$ Como demostración de esta afirmación, valga mencionar el video que se hizo viral en 2019, en que se muestra la tranquilidad de los pasajeros en el aeropuerto de Santiago durante un movimiento telúrico. GuerRa (2019).

${ }^{13}$ Véase Mellafe (2004), p. 279 y ss.

${ }^{14}$ En este sentido afirma Rolando Mellafe: "el hombre americano y chileno se ha definido como esencialmente telúrico. Pero lo telúrico no es un simple amor a la tierra, ni una simple afinidad con lo natural; es un diálogo constante e inconsciente de la siquis con la naturaleza. El acontecer infausto tiraniza este diálogo, obliga a toda una sociedad a enfrentarse, a través de su yo con los estratos más profundos de su existencia natural, en el alba de su propia siquis. Las tensiones que el reiterado encuentro produce, el terror que muchas veces nos inspira, provoca fenómenos colectivos que se traducen en modos de ser y de actuar: el amor y el desamor al terruño, por ejemplo. Se ama el lugar donde se nace; pero se escapa de allí. Se ama a la mujer, a la madre y a la familia, pero se les abandona. La mujer permanece más, por otro tipo de ataduras, pero por ese mismo hecho debe asumir un papel más realista y de mayor entereza, lo que explica mucho de sus conductas históricas". Cfr. Mellafe (2004), p. 287.

${ }^{15}$ Esta opinión es compartida por Hernán Corral, quien luego del 27F advierte: “a pesar de los grandes sismos que han azotado al país, se encuentra poca jurisprudencia sobre el tema". Corral (2010), p. 464.

${ }^{16}$ Véase Memoria Chilena (SD) y Corfo (SD). 
literalmente levantar al país en ruinas, mientras que a raíz del terremoto de Valdivia de 1960 tiene inicio lo que luego será la Onemi, cuya misión será esencialmente diseñar un plan de contingencia para reaccionar frente a la catástrofe y acudir en auxilio de la población ${ }^{17}$. Sin embargo, sin perjuicio de algunos intentos en tal dirección, no puede hablarse de una institucionalidad destinada de forma sistemática a la gestión del riesgo y a la prevención del desastre, lo que recién se ha venido produciendo con posterioridad al 27 de febrero de 2010. Este episodio marca un antes y un después en la forma de enfrentar el desastre natural por parte del Estado.

En efecto, a consecuencia del devastador terremoto y posterior tsunami de 2010, se generó en las autoridades y en la comunidad académico-científica la conciencia de la necesidad de contar con centros especializados en el estudio de los desastres naturales, desde sus múltiples dimensiones ${ }^{18}$, así como de disponer de un organismo público que se ocupe no solo de la emergencia, sino de todo el ciclo del desastre ${ }^{19}$. Asimismo, por primera vez en la historia nacional, se han recolectado datos estadísticos tanto de la cantidad y magnitud de los desastres naturales como de sus causas, más allá de los fenómenos naturales que los desencadenan, los que han permitido cuantificar los costos de los desastres ${ }^{20}$.

${ }^{17}$ Véase Onemi (1974).

${ }^{18}$ En el ámbito académico cabe citar la creación de dos centros multidisciplinarios abocados al estudio de los desastres naturales: Cigiden (www.cigiden.cl/), liderado por la Facultad de Ingeniería de la Pontificia Universidad Católica de Chile y Citrid (http://citrid.uchile.cl/).

${ }^{19}$ Con esta finalidad se ha puesto en marcha una serie de iniciativas, $v$. gr. se presentó el proyecto de ley que establece el "Sistema nacional de emergencia y protección civil" y crea la "Agencia Nacional de Protección Civil”, actualmente en segundo trámite constitucional, véase Boletín legislativo 7550-06. Se puso en marcha una iniciativa del Ministerio de Defensa, en orden a explicar a los particulares los principales riesgos de desastres naturales y cómo ponerse a salvo de sus efectos, véase www.defensa.cl/emergencias/riesgos-y-desastresnaturales/ [fecha de consulta: 1 de octubre de 2020]. El Sernageomin ha establecido un sistema de vigilancia volcánica que, a su vez, genera una "alerta volcánica", con distintos colores dependiendo del grado de probabilidad de que se produzca una erupción, véase www.sernageomin.cl/red-nacional-de-vigilancia-volcanica/ [fecha de consulta: 1 de octubre de 2020]. Se creó la Plataforma Nacional Para la Reducción del Riesgo de Desastre, liderado por la Onemi, véase www.onemi.cl/plataforma-de-reduccion-de-riesgos-de-desastres/ [fecha de consulta: 1 de octubre de 2020]. El 18 de febrero de 2017 se publicó el decreto supremo 1512, del Ministerio del Interior y Seguridad Pública, el cual establece la Política nacional para la gestión de riesgo de desastres.

${ }^{20}$ V. gr., en el año 2015, Chile ocupó el sexto lugar en la lista de los países que mayores daños económicos sufrieron a causa de desastres naturales en el mundo, con un total de treinta y un millones de dólares. Fuente: www.unisdr.org/we/inform/publications/47804 [fecha de consulta: 1 de junio de 2016]. 


\section{SURGIMIENTO Y CONSOLIDACIÓN \\ DE LA RESPONSABILIDAD POR DAÑOS DERIVADOS DE FENÓMENOS NATURALES}

Tal y como se indicó en el apartado anterior, los fenómenos naturales extremos y los daños que ellos ocasionaban, hasta hace no muchos años, eran considerados por la población chilena como fatalidades, que debían soportarse por el hecho de vivir en Chile. En lo que aquí importa, ello determinaba la ausencia casi total de demandas de responsabilidad civil asociadas a esos eventos, pues se los consideraba fuerza mayor o caso fortuito, en palabras simples, infortunios que no daban lugar a responsabilidad. Ese escenario comenzó a cambiar a raíz de una serie de factores concomitantes que llevaron a la proliferación de demandas de responsabilidad asociadas a este tipo de eventos, tanto contra particulares como contra el Estado.

Entre tales factores, por un lado, está el hecho ya advertido de que en el ámbito internacional comenzó a tomarse conciencia de la necesidad y posibilidad de evitar los desastres naturales, a través de la implementación de medidas de mitigación y gestión del riesgo tanto de origen natural como antrópico. En efecto, en el ámbito global, la importancia asignada a la gestión y prevención de los desastres, independientemente de su origen natural o antrópico, es tal que ha dado lugar a una oficina especializada de la ONU (UNISDR), que ha propiciado una serie de instancias para instaurar políticas relativas a la gestión de riesgo de desastres. La más importante de tales iniciativas es la Conferencia Mundial sobre la Reducción de los Desastres, celebrada en Kobe, Hyogo, Japón, que dio lugar al llamado MAH para 2005-2015, destinado al "aumento de la resiliencia de las naciones y las comunidades ante los desastres", suscrito por Chile en el mismo 2005, y reemplazado por el Marco de Sendai para la Reducción del Riesgo de Desastres 2015-2030. En el preámbulo del documento que recoge el marco de acción Hyogo se señala expresamente:

"las pérdidas que ocasionan los desastres van en aumento ${ }^{21}$, acarreando graves consecuencias para la supervivencia, la dignidad y los medios de vida de los seres humanos, en particular los pobres, y para el desarrollo logrado a costa de mucho esfuerzo. El riesgo de desastres es un motivo de creciente preocupación mundial ${ }^{22}$

${ }^{21}$ En efecto, las últimas mediciones de los expertos públicamente disponibles señalan que, en el año 2018, en el ámbito mundial, las pérdidas asociadas a desastres naturales y antrópicos alcanzaron los ciento sesenta y cinco mil millones de dólares. Mientras que en el bienio 2017-2018 las pérdidas asociadas de forma exclusiva a desastres naturales alcanzaron doscientos diecinueve millones de dólares. Swiss RE (2019).

${ }^{22}$ Como muestra de esta preocupación puede señalarse el surgimiento en el ámbito internacional de varias revistas especializadas en la materia, que cubren los diversos campos 
cuyo impacto y acción en una región pueden repercutir en los riesgos de otra, y viceversa" ${ }^{23}$.

De esa manera, bajo la premisa de que el fenómeno en sí es inevitable, pero eso no necesariamente implica que el daño ocasionado por él lo sea, la población chilena comenzó a desechar la fatalidad asociada al fenómeno natural extremo, comenzando a buscar a los "responsables" del daño ${ }^{24}$, que se identifican con aquella o aquellas personas que tenían el deber jurídico de impedir que el fenómeno se transformara en una fuente de daño para la comunidad o, bien, que con su actuar posibilitaron que el fenómeno se tornara dañino, esto es, de quienes estaban a cargo de la gestión del riesgo ${ }^{25}$. Esta idea puede constatarse desde dos perspectivas. Por un lado, los estudiosos de las ciencias sociales han puesto en evidencia el cambio de mentalidad del chileno en relación con los desastres naturales, que de asumir los desastres con "estoicismo" y "resignación" centró su atención en la búsqueda de responsables por su ocurrencia, desechando así la fatalidad de los mismos ${ }^{26}$. Por otro lado, la jurisprudencia analizada, en especial aquella relativa a las demandas en contra del fisco u otros

de la ciencia. V. gr. International Journal of Disaster Risk Reduction (UK); Revista internacional de desastres naturales, International Journal of Disaster Resilience in the Built Environment (UK); Jàmbá:Journal of Disaster Risk Studies; Disaster Prevention and Management (Sud África); Law, Probability and Risk (UK). accidentes e infraestructura civil (Costa Rica) y The International Journal of Disaster Risk Science (China).

${ }^{23}$ Cfr. Marco de Acción de Hyogo para 2005-2015, p. 1.

${ }^{24}$ No se trata de un fenómeno exclusivamente chileno, al contrario. Así, a propósito de la realidad estadounidense, afirma Denis Binder, que después de un desastre los abogados presentan una gran cantidad de demandas en contra de todos los potenciales responsables, exceptuando solo a Dios (juego de palabras, en alusión al concepto de caso fortuito como act of God). Véase Binder (1996), p. 2 y ss.

${ }^{25}$ Como explican Marta Infantino y Elinim Zervogianni: "Because of the improved human capability of understanding and (to some extent) controlling diseases, hurricanes, earthquakes and climate, these events have ceased to appear to be unalterable fates and have come to be seen instead as having their origins in human action or inaction, as the products of inappropriate policies or interventions. The growth of human knowledge, advances in technical feasibility and rising expectations of amenity and safety may thus expand the sphere of what is considered dan injury caused by human agent, propelling the so-called 'natural' events from the real off ate into the real of accidents for which someone could be held responsible". Cfr. Infantino y Zervogianni (2017), p. 7.

${ }^{26}$ En este sentido, afirman Bárbara Silva y Alfredo Riquelme: “el adjetivo 'estoico' se repetía con frecuencia, en alusión al destino de enfrentar una y otra vez la pérdida de posesiones materiales en el caso de Chile, por la acción imprevista de la naturaleza, y no alterarse mayormente por ello”. Cfr. Silva y RiQuelme (2018), p. 72. Empero, una situación diametralmente opuesta se observa luego del $27 \mathrm{~F}$, en que el "evento natural" pasa a segundo plano, tomando primacía las supuestas "ausencia de políticas públicas y la negligencia de las autoridades”. Cfr. Ugarte y SAlgado (2014), p. 138. 
organismos públicos, dan cuenta del empleo de la noción de gestión de riesgo como deber de cuidado, para lo cual se recurre tanto a la normativa interna como internacional alusiva a este concepto, con el fin de fundar la responsabilidad del Estado chileno ${ }^{27}$.

Adicionalmente, están el hecho de que la prosperidad económica trajo consigo la proliferación de las demandas de responsabilidad civil de toda índole ${ }^{28}$ y el que la masificación de la educación y las comunicaciones llevó a que las personas se hicieran más conscientes de sus derechos y del papel del Estado en la salvaguarda de su integridad. En virtud de esto último, las actividades estatales tendientes a proteger a la población frente a fenómenos naturales extremos dejaron de considerarse una actividad graciosa del Estado y fueron vistas como un imperativo constitucional ${ }^{29}$.

La combinación de tales factores conllevó la multiplicación de las demandas de responsabilidad civil, reclamando la indemnización de los daños sufridos a raíz de fenómenos naturales extremos. Sin perjuicio de la posibilidad de identificar casos aislados anteriores, el momento histórico de este cambio sistemático de escenario puede, desde luego, situarse en la primera década de este siglo, cuando comienzan a proliferar las demandas y las sentencias condenatorias por este tipo de daños, llegando a una expansión exponencial a raíz del terremoto y tsunami de $2010^{30}$.

III. LOS FENÓMENOS NATURALES COMO CONDICIONES NECESARIAS DEL DAÑO: LA CONFIGURACIÓN DE LA RESPONSABILIDAD POR ERRÓNEA GESTIÓN DEL RIESGO EN LA JURISPRUDENCIA CHILENA

Como se anticipó, los fenómenos de origen estrictamente natural dependen de las condiciones geográficas, geológicas, atmosféricas, etc. del lugar en que ocurren, de manera que en su producción no tiene influencia la actividad humana, justamente de ahí deriva el hecho de que tradicional-

${ }^{27}$ V. gr. Alba Oñate Sanhueza con Fisco de Chile (2016); Diodina Lefiqueo Pincheira con Fisco de Chile (2017); Manuel Escalona Allendes y otros con Fisco de Chile (2017); René Pinto Flores y otros con Fisco de Chile (2018) y Guillermo Ramón Pérez Freire y otros con Fisco de Chile (2019).

${ }^{28}$ Se trata de un fenómeno común a todos los países, pues las demandas se producen en la medida que los causantes del daño tengan bienes con qué responder, de lo contrario, la víctima renuncia de manera anticipada a demandar.

${ }^{29}$ De esto dan cuenta las numerosas demandas de responsabilidad por falta de servicio, pues todas ellas se fundan en que el Estado tiene el deber de proteger a la población, lo cual incluye gestionar el riesgo asociado a los fenómenos naturales extremos, impidiendo que estos se transformen en una fuente de daños para los administrados.

${ }^{30} \mathrm{La}$ copiosa jurisprudencia a que dio lugar el $27 \mathrm{~F}$ ha sido doctrinariamente recopilada en varios textos. Véanse Ríos (2017); Alarcón y Muñoz (2018); Farfarello (2019) y TAPIA (2019), p. 139 y ss. 
mente se les asociase a eventos de fuerza mayor o caso fortuito. En efecto, una constante en la jurisprudencia analizada para la elaboración de este texto, es que el demandado invoca el fenómeno natural para fundar la eximente de caso fortuito ${ }^{31}$.

De esa manera, en principio, opera la máxima casum sentit dominus. Es la víctima quien debe soportar las consecuencias dañinas derivadas de los fenómenos naturales. Esta máxima, que constituye la regla general en la materia, puede ser alterada solo cuando la víctima acredite que un determinado sujeto (público o privado) tenía el deber jurídico de impedir que el fenómeno deviniera en un daño, el cual no cumplió culpablemente o, bien, acredite que, aunque el fenómeno es una condición necesaria para la ocurrencia del daño, este no se habría producido de no haber mediado la actividad negligente del demandado. Así las cosas, la responsabilidad civil asociada a los fenómenos naturales puede consistir en una responsabilidad por omisión o, bien, por acción. A continuación, se analizará cada una de estas dos perspectivas.

\section{Responsabilidad por omisión}

Tratándose de la responsabilidad por omisión, conforme a las reglas generales que gobiernan a esta clase de responsabilidad ${ }^{32}$, la jurisprudencia se ha ocupado de identificar la fuente del deber jurídico que impone al demando la necesidad de evitar el siniestro, la cual puede encontrarse en una norma legal (entendido ley en sentido amplio) ${ }^{33}$, en un contrato administrativo de concesión de obra pública ${ }^{34}$, en un compromiso adqui-

${ }^{31}$ Sobre la relación entre fenómenos naturales y casos fortuitos, especialmente en lo relativo a la jurisprudencia del $27 \mathrm{~F}$, véase TAPIA (2019), p. 139 y ss.

${ }^{32}$ Sobre la responsabilidad por omisión, véase SAn MARTín (2011), pp. 199-2013.

${ }^{33}$ Este es el caso de la responsabilidad del fisco y, en general, de las instituciones públicas por falta de servicio, en que la jurisprudencia se ha ocupado de identificar la norma de la cual emana el deber de la Administración cuya infracción resulta relevante a efectos de la producción del daño. V. gr. María Angélica Rivera Araneda con Ilustre Municipalidad de La Unión (2001) y Mario Quezada Silva y otros con Fisco de Chile (2017). Asimismo, tratándose de otros cuerpos normativos que imponen deberes de salvaguarda, como es el Código del Trabajo respecto de los empleadores para con los trabajadores. De esta manera, un daño derivado de un fenómeno natural puede dar lugar a la responsabilidad civil del empleador, siempre y cuando haya infringido la obligación de seguridad que le impone el art. 184 del Código del Trabajo. Véase Francisca Saravia Núñez con Compañía Siderúrgica Huachipato S.A. (2016).

${ }^{34}$ Así, en el caso de las concesionarias de carreteras, resultan responsables de aquellos daños asociados a eventos naturales, que ellas, en virtud de sus deberes como concesionarias, debían evitar. V. gr. Helmar Roland Viertel Molina con Ruta de los Ríos Sociedad Concesionaria S.A. (2019). 
rido por el demandado con las autoridades administrativas ${ }^{35}$ e, incluso, en la confianza que el demandado ha generado a raíz de sus actividades previas $^{36}$. Tales ideas pueden ser verificadas de manera bidireccional.

Por un lado, están los casos que niegan la responsabilidad porque no se configura el deber jurídico de actuar que supuestamente tenía el demandado. En este sentido, a modo de ejemplo, resulta oportuno citar la sentencia de la Corte Suprema de 26 de mayo de 2005, dictada a propósito de los daños sufridos por varias casas en la ciudad de Viña del Mar, con ocasión de un alud provocado por las copiosas lluvias que cayeron sobre esta ciudad en el año 1997. En tal fallo, confirmando la sentencia de apelación que rechazó la falta de servicio, la Corte Suprema textualmente resuelve:

“34 $34^{\circ}$ [...] Esta Corte no puede sino concordar con dicho predicamento, pues para que concurra falta de servicio, es menester que exista una obligación legalmente consagrada, respecto de determinado órgano de la administración, de prestar alguno concreto y específico. Entonces, la responsabilidad operará cuando el servicio a que por ley está obligado no se preste, se cumpla en forma tardía, o de manera insuficiente, y luego, exista relación de causalidad entre el incumplimiento de la obligación o cumplimiento tardío o inadecuado, y el daño producido;

${ }^{35}$ Este es el caso de la causa Guacolda Adriana Carrasco Pérez y otros con Empresa Nacional de Electricidad en que se condena a Endesa a indemnizar a los propietarios ribereños del río Biobío, a raíz de la inundación sufrida el año 2006. La decisión se funda en que: "conforme al Estudio de Impacto Ambiental presentado por Endesa al Estado de Chile para obtener la aprobación del proyecto, la demandada quedó obligada a operar las compuertas de su embalse de manera de alcanzar el objetivo concreto consistente en que 'todas las crecidas serán amortiguadas en forma importante por el embalse Ralco'”. Lo cual no ocurrió, sino que se produjo un impacto "menor" en la reducción de la crecida. Véase Guacolda Carrasco Pérez y otros con Empresa Nacional de Electricidad (2015).

${ }^{36}$ Así emana del fallo en que se condena a la Municipalidad de Lebu a raíz del desprendimiento de rocas que causó la muerte de un visitante ocurrido en las Cavernas de Benavides, lugar turístico promocionado por la municipalidad, pero que ella alegó era de propiedad privada. Al respecto la Corte Suprema sostuvo: "Que frente a la alegación de infracción a lo preceptuado en leyes reguladoras de la prueba, yerro que se hace consistir en la errónea ponderación de la evidencia instrumental reseñada en el considerando quinto, se debe decir que a la luz de los hechos referidos precedentemente la titularidad en el dominio del inmueble por el que atraviesa el camino de marras deja de ser relevante, puesto que encontrándose establecido que el lugar donde acaeció el accidente es un sector ampliamente promocionado por el Municipio, respecto del cual ejecutaba actos de disposición, como mantener estacionamientos y organizar diversas actividades de esparcimiento abiertas para la comunidad, cabe exigirle haber desplegado el cuidado y diligencia necesarias con el fin de evitar daños a la integridad física de las personas, más aun si la propia Municipalidad incentivaba la visita a ese sitio mediante la utilización del camino en que sucedió el accidente”. Cfr. María Arévalo Fuentealba con Municipalidad de Lebu (2013). 
$\left.35^{\circ}\right)$ Que, en el presente caso, lo anterior no ocurre, porque no se ha invocado una falta de un servicio preciso, directo, concreto y determinado que la ley haya obligado a prestar a la municipalidad demandada, en relación con los hechos de autos y cuya inobservancia haya producido, también de modo directo, los perjuicios de que se reclama y se le hace responsable. Para configurar una situación jurídicamente vinculante, respecto de la entidad demandada, como la que se invoca en la demanda, resulta por completo insuficiente la existencia de la obligación genérica de administrar la comuna, o los bienes municipales o nacionales de uso público, incluido el subsuelo, que cabe a las municipalidades, según la normativa traída a colación por el recurso de casación de fondo, o la de aplicar las disposiciones sobre construcción y urbanización, sin perjuicio de que los hechos de autos no se vinculan a las obligaciones de atender el aseo y ornato de la comuna y de extraer la basura, que guardan relación con funciones de limpieza, embellecimiento y extracción de desperdicios, también de orden genérico" ${ }^{37}$.

De esta manera, la sentencia descarta la responsabilidad de la municipalidad fundado en que ella no tenía un deber de cuidado en orden a impedir la verificación de las inundaciones. Sin perjuicio de la claridad de la sentencia, cabe señalar que ella es particularmente exigente en cuanto a la configuración del deber de cuidado, pues exige una norma específica que imponga el concreto deber de actuación. En otros casos, en especial en la jurisprudencia más reciente, sin embargo, los sentenciadores son menos exigente en este sentido. En efecto, para imponer responsabilidad a las municipalidades, aluden a un deber más bien genérico de cuidado del espacio público sometido a su jurisdicción, así como de los habitantes de la comuna, derivado de la normativa que regula a estas entidades ${ }^{38}$.

${ }^{37}$ Cfr. Luis Felipe Baeza Balbontín con Ilustre Municipalidad de Viña del Mar (2005). Un razonamiento en la práctica idéntico al de esta sentencia se aprecia en el fallo de 18 de octubre de 2010, en cuanto confirma la decisión de la Corte Apelaciones de Concepción, que rechaza la falta de servicio del MOP y del Serviu, por las inundaciones ocurridas en junio de 2005. Véase Carlos Vargas Alvarado con Fisco y otro (2010). Véase también Humberto Senerega Puga con I. Municipalidad de Viña del Mar (2007). Asimismo, cabe destacar el fallo que rechaza la demanda en contra de la Municipalidad de Quilpué en razón de que el predio en que ocurrió el daño es propiedad privada, sin que quepa al municipio la obligación de fiscalización. Iván Espíndola Canelo y otra con Gloria Arbulo Núñez y otros (2016).

${ }^{38}$ V. gr. Marta María Araya Muñoz con I. Municipalidad de Peñaflor (2007); Manuelita Labbé Correa y otro con I. Municipalidad de San Bernardo (2007); Luisa Torres Puentes y otro con I. Municipalidad de Talcahuano (2016); María Arévalo Fuentealba con Municipalidad de Lebu (2013) y Sociedad Pastelería Arraya Limitada con I. Municipalidad de Talcahuano y otro (2016). 
Por otro lado, están aquellos casos que identifican la norma que impone la obligación con la consiguiente condena por no haberla observado. Así puede observarse en la sentencia de 16 de noviembre de 2017 emitida por la Corte Suprema a propósito de la muerte de un recolector de orilla en la isla Mocha a raíz del tsunami de $27 \mathrm{~F}$. En este caso, el máximo tribunal se ocupa de identificar el deber del Estado, que se traduce en medidas que debía adoptar como parte del plan de protección civil y de prevención de desastres. Al efecto, la Corte señala:

"Que, como se indicó en los motivos anteriores, al Estado le correspondía, y así lo había asumido en la normativa de emergencia reseñada, una obligación de prevención y regulación tendiente precisamente a evitar las consecuencias de estas catástrofes, de cuya infracción se deriva precisamente el sustento de su responsabilidad en este caso.

De esta manera, correspondía al Estado definir áreas vulnerables, preparar en cada caso el contexto de emergencia y educar a la población según las particularidades de cada zona, pues por ello, los planes de emergencia tiene una estructura funcional y territorial que importa conocer sectorialmente cuales son aquellas áreas que presentan mayor vulnerabilidad en estos hechos. Así, el Estado, en conocimiento por medio de sus agentes del ejercicio de esta actividad de recolección primaria, por personas de escasos recursos importaba una obligación de preparación previa que permitiese otorgar a la población elementos de resguardo más elaborados, no solo en la determinación de las zonas, en el señalamiento de vías de evacuación y en la prohibición de pernoctación en lugares más expuestas como la de Punta de Lobos.

La omisión de aquella obligación no ha estado amparada por la exculpación del terremoto y maremoto del 27 de febrero de 2010 y, de la infracción de aquella es que se deriva la responsabilidad del Estado para con la víctima en este caso, quien, de haber sido advertido, preparado, regulado, capacitado y enseñado, habría estado en condición de adoptar medidas más sofisticadas de preparación que le hubieran permitido tener la opción de salvar su vida"39.

Incluso, hay casos en que se acoge la responsabilidad respecto de algunos demandados y se niega respecto de otros por el hecho de existir solo respecto de los primeros normativa que le imponía el deber de evitar el daño. Este es el caso de la sentencia de 30 de enero de 2013, relativa a

\footnotetext{
${ }^{39}$ Diodina Lefiqueo Pincheira con Fisco de Chile (2017).
} 
la inundación ocurrida en el complejo habitacional Alto Jahuel II el año 2002, donde se demandan junto con la inmobiliaria, a la Municipalidad de Pudahuel, al Ministerio de Transportes y Telecomunicaciones, al Minvu $\mathrm{y}$ al Serviu ${ }^{40}$. En este fallo se acoge la acción respecto de la inmobiliaria, para lo cual se recurre a la normativa del Código Civil relativa al contrato de construcción ${ }^{41}$, y respecto del Serviu, en atención a que no habría cumplido con la obligación legalmente impuesta de mantener y reparar los ductos de evacuación de aguas lluvias. Por su parte, se rechazó respecto de los demás demandados ${ }^{42}$. Para exonerar a la Municipalidad la Corte Suprema afirma:

"Al respecto cabe consignar que, como lo manifiesta la Sra. Juez a quo en la motivación trigésima novena del fallo en alzada, no existe cargo alguno que formular a dicha entidad, pues en la materia de que se trata le está vedado inmiscuirse en los aspectos técnicos de la construcción de las diversas obras de que se trata [...]”.

${ }^{40}$ Patricia Soto González y otros con Jahuel Ingeniería y Construcción Limitada y otros (2013).

${ }^{41}$ Sobre esta condena, resulta relevante señalar que el mismo barrio se había inundado con anterioridad, en el año 2000, respecto de la cual los tribunales resolvieron: "que no existe fuente de obligación que constriña a la demandada a responsabilizarse por el episodio de inundación de que fue objeto el Barrio Alto Jahuel Dos, los días trece y catorce de junio de dos mil, toda vez que ella cumplió cabalmente con la obligación legal que le imponía la Ordenanza General de la Ley General de Urbanismo y Construcciones, D.S. 47 del Ministerio de Vivienda y Urbanismo, que en su artículo 1.1.3. establece que las solicitudes de aprobaciones o permisos presentadas ante las Direcciones de Obras Municipales serán evaluadas y resueltas conforme a las normas vigentes en la fecha de su ingreso. Tratándose de normas técnicas de instalaciones o de urbanización, deberán ser evaluadas y resueltas por los organismos competentes de conformidad a las normas vigentes en la fecha de ingreso de la solicitud del permiso respectivo ante la Dirección de Obras Municipales. // De este modo, los jueces del mérito dan por establecido que Jahuel Ingeniería y Construcción Limitada diseñó un proyecto de evacuación de aguas lluvias para el conjunto habitacional Barrio Alto Jahuel Dos, el cual fue aprobado por la Dirección de Obras de la Municipalidad de Pudahuel, y posteriormente ejecutado y recepcionado a plena conformidad de dicho organismo, concluyendo en definitiva que la actora no logró probar el presupuesto de hecho que sirve de fundamento a la demanda, esto es, que el siniestro que afectó al loteo se produjo por fallas o defectos de proyección, diseño, construcción o ejecución, del sistema colector de aguas lluvias del referido loteo”. Cfr. Emilio Sahurie Luer con Jahuel Ingeniería y Construcción Limitada (2007).

${ }^{42}$ Respecto de los ministerios la sentencia de primera instancia había ya concluido que ellos "no gozan de facultades ejecutivas u operativas que les permita intervenir en las urbanizaciones que realicen los particulares como es en el caso sublite". Soto González Patricia Del Carmen y otros con Jahuel Ingeniería y Construcción Limitada y otros (2007). 
Por su parte, para condenar al Serviu señala:

"Que de la norma transcrita ${ }^{43}$ se desprende que por ella se entregó al Estado la responsabilidad de velar por la existencia de 'sistemas de evacuación y drenaje de aguas lluvias que permitan su fácil escurrimiento y disposición e impidan el daño que ellas puedan causar a las personas, a las viviendas y, en general, a la infraestructura urbana', estableciéndose para tal fin la creación de dos redes, una, la primaria, a cargo del Ministerio de Obras Públicas, y otra, la secundaria, del de Vivienda y Urbanismo, precisando la disposición que la "proyección, construcción, reparación y mantención" de esta última corresponde al Servicio de Vivienda y Urbanización'.

$[\ldots]$

En el caso sublite ha quedado de manifiesto que el demandado Servicio de Vivienda y Urbanización incurrió en la mentada falta de servicio, pues, pese a encontrarse obligado a prestar el consistente en la reparación y mantención de las instalaciones del sistema de evacuación y drenaje de aguas lluvias existente en el lugar de los hechos, después de producida la inundación ocurrida los días 13 y 14 de junio de 2000, no lo hizo, con lo que dicha prestación no fue procurada en lo absoluto.

[...] Que, asentada la concurrencia en la especie de la falta de servicio imputada al Servicio de Vivienda y Urbanización, forzoso resulta concluir que dicha omisión lo torna responsable de los perjuicios que, como consecuencia de dicha inactividad, hubieren sufrido los actores".

En síntesis, la responsabilidad por omisión se funda en la infracción de un deber de actuación, que en el caso de los fenómenos naturales se condice con la idea de gestión del riesgo, la que puede exigir una actuación anterior al fenómeno o, bien, una vez que este ya ha iniciado o, incluso, concluido. Tratándose de la actuación anterior al fenómeno, la actividad del sujeto estará dirigida a la prevención de los daños y generalmente su conducta consistirá en la adopción de medidas de mitigación del riesgo. Una vez que el fenómeno ya ha iniciado o, bien, terminado ${ }^{44}$, se tratará de

${ }^{43}$ Art. 1 de la Ley n. ${ }^{\circ} 19525$.

${ }^{44}$ Esto claramente dependerá de la duración del fenómeno natural. Así, en el caso de un temporal o de una erupción volcánica con varios días de desarrollo, la gestión de la emergencia se lleva acabo durante el transcurso del fenómeno. En caso de fenómenos de breve duración, en cambio, como son típicamente los terremotos, la gestión de la emergencia será posterior al evento. 
la gestión de la emergencia. Como se dijo antes, en Chile la atención ha estado tradicionalmente puesta justo en la gestión de la emergencia, pero en los últimos años se ha evolucionado hacia la gestión del riesgo en su integridad, lo que incluye la etapa preventiva. Esta idea se refleja también en la jurisprudencia. En lo sucesivo se analizan cada una de estas etapas.

a) La responsabilidad por omisión en la gestión de la emergencia.

Deber de actuar en forma concomitante o posterior

a la ocurrencia del fenómeno

Una vez iniciado u ocurrido un fenómeno natural extremo es muy importante que la reacción de los involucrados en el hecho sea eficaz y oportuna, pues eso les permitirá ponerse al seguro del peligro. En este sentido existen normas que imponen a ciertos sujetos el deber de salvaguardar los intereses materiales y ajenos frente a la ocurrencia de ese tipo de fenómenos. Si estos sujetos no actúan serán jurídicamente "causantes" $y$, por consiguiente, responsables del daño que habrían podido evitar ${ }^{45}$. En la jurisprudencia nacional de los últimos años esta idea se aprecia con claridad en algunos casos relativos al $27 \mathrm{~F}$, en que se reprocha a las autoridades administrativas el no haber dado la alerta de tsunami estando obligada y en condiciones de hacerlo ${ }^{46}$. A modo de ejemplo, en tal sentido puede citarse la sentencia de 7 de junio de 2016, relativa al arribo del tsunami a la isla Juan Fernández. Este fallo señala de manera expresa que para establecer la responsabilidad de la Administración:

"[...] habrá de resaltarse que la omisión o abstención de un deber jurídico de la Administración generará responsabilidad para aquella si se trata del incumplimiento de un deber impuesto por el ordenamiento jurídico. En otras palabras, cuando se constate la ausencia de actividad del órgano del Estado debiendo aquella actividad haber existido, disponiendo de los medios para ello" ${ }^{\prime 4}$.

${ }^{45}$ En efecto, la responsabilidad fundada en la omisión se caracteriza justamente porque solo en virtud de un deber jurídico de actuar es posible considerar "causante" a quien en los hechos se limita a dejar que las cosas sigan su curso sin natural. Sobre el particular, SAn Martín (2012), p. 302 y ss. y San Martín (2011), passim.

${ }^{46}$ Véase Alba Oñate Sanhueza con Fisco de Chile (2016); Robinson Green Gómez y otro con Fisco de Chile (2017); Manuel Escalona Allendes y otros con Fisco de Chile (2017); Víctor Arriagada Sepúlveda y otros con Fisco de Chile (2018); Rivera Muñoz Viviana con Fisco de Chile (2019) y Guillermo Ramón Pérez Freire y otros con Fisco de Chile (2019).

${ }^{47}$ Alba Oñate Sanhueza con Fisco de Chile (2016). En sentido contrario se ha resuelto que no se configura la responsabilidad de la concesionaria de carretera por los accidentes sufridos a raíz de una densa neblina, sumada al humo generado por las viñas aledañas, 
A su turno, luego de revisar la normativa que regula a los distintos organismos públicos involucrados en la gestión del riesgo de desastre, la sentencia concluye:

"Que es manifiesto entonces que tales entes públicos fueron creados para funcionar ante la ocurrencia de catástrofes naturales, esto es, su funcionamiento fue concebido cuando existan circunstancias anormales o extraordinarias, por lo que no es posible aceptar, como postula el demandado, que la ocurrencia de un terremoto de una intensidad de 8,8 grados Richter implique desde ya la inexigibilidad de las tareas encargadas a dichos servicios estatales. Es a la luz de dichas circunstancias excepcionales que debe examinarse el cometido que ejecutó la Administración”48.

En síntesis, la jurisprudencia chilena reconoce que la ocurrencia de un fenómeno natural impone al sujeto encargado de la gestión del riesgo la necesidad de actuar a fin de evitar sus consecuencias dañinas. Una omisión en este sentido comporta asumir la responsabilidad por los daños que hubieran podido evitarse con tal actuación. En todo caso, también se reconoce que esta actuación debe ser en el marco de las posibilidades que concretamente tenía el demandado, según las circunstancias del caso. En este sentido, se rechaza la demanda intentada contra de una concesionaria de carretera, entre otras razones, por el hecho de que:

"[...] la demandada en ningún caso se encontraba en condiciones de instalar, aproximadamente a los 6 o 10 minutos de ocurrido el terremoto grado 8,8 la señalética que advirtiera el peligro, 'por cuanto, es un hecho notorio y de público conocimiento que dicho movimiento telúrico estuvo seguido de fuertes y constantes réplicas, lo que a lo más permitía a la concesionaria, sólo detectar por sus mecanismos internos de control de autopista, el estado en que se encontraban las carreteras concesionadas o dicha concesión; a lo que debe sumarse que el corte de energía eléctrica' ${ }^{49}$.

en razón de que "no se acreditó la concurrencia de los requisitos exigidos por la ley para que proceda la acción intentada, ya que no existe una omisión o acción ilícita ni culposa de la parte de la demandada como tampoco una relación causal entre el hecho ilícito y el daño reclamado". Cfr. Elsa Sara Cabezas Paillali con Sociedad Concesionaria Rutas del Pacifico S.A (2020).

${ }^{48}$ Alba Oñate Sanhueza con Fisco de Chile (2016).

${ }^{49}$ Alejandra Sotta Bunster y otros con Sociedad Concesionaria Autopista (2015). 
b) El deber de gestión preventiva del riesgo.

Responsabilidad por la omisión de las actividades

que habrían evitado que el fenómeno natural generara daño

Ante a la ocurrencia de un fenómeno natural extremo, la capacidad de reacción de la población depende de qué tan preparada esté para enfrentar el evento. Esto es justo lo que explica que en la actualidad el enfoque de esta materia no sea de reacción ante la emergencia, sino de prevención y gestión del riesgo ${ }^{50}$. En consecuencia, para juzgar la responsabilidad civil del demandado no basta con analizar su comportamiento posterior a la ocurrencia del evento, sino que es necesario analizar las medidas preventivas de gestión del riesgo que estaba jurídicamente llamado a adoptar. Así las cosas, el juicio de responsabilidad en este caso versa sobre la actuación del sujeto frente a la amenaza, lo que implica el análisis de un ciclo complejo que, en síntesis, puede resumirse en las siguientes fases:

i) la identificación y zonificación de los riesgos o amenazas,

ii) la detección de las vulnerabilidades,

iii) la determinación de las medidas idóneas para impedir que una amenaza se transforme en daño y

iv) la correcta implementación de estas medidas.

Una negligencia en cualquiera de estas fases es apta para generar responsabilidad por los daños que el fenómeno natural acarree.

En términos jurídicos estrictos, el ciclo recién descrito se relaciona con el caso fortuito o fuerza mayor, específicamente con la previsibilidad del evento y la resistibilidad del mismo y/o sus consecuencias ${ }^{51}$. En efecto, por lo regular los demandados a raíz de un desastre invocan el caso fortuito o fuerza mayor como eximente de responsabilidad en este caso, defensa que es acogida o desechada dependiendo de si cumplió o no de forma cabal con la secuencia o si, por el contrario, incurrió en alguna negligencia. Esto se aprecia a lo largo de toda la jurisprudencia analizada para la elaboración de este texto ${ }^{52}$.

${ }^{50}$ SANTINI (2015), passim.

${ }^{51}$ Ampliamente sobre la importancia de la previsibilidad y la resistibilidad para configurar la responsabilidad por los daños derivados de fenómenos naturales, puede verse la sentencia dictada a propósito de la inundación del centro de la ciudad de Punta Arenas, el año 2012. Véase Rodrigo Araya Carreño y otros con Fisco de Chile y otros (2020). Un análisis igualmente extenso, con un resultado diametralmente opuesto, puede verse en la sentencia de 12 de junio de 2013, dictada a propósito de la caída de un árbol sobre un automóvil en la carretera Austral. Véase Enzo Danke de la Harpe y otros con The Conservation Land Trust y otros (2013). En este caso, véase también el extenso voto en contra del ministro Sergio Muñoz, quien es del parecer que en la especie no se reúnen los requisitos del caso fortuito.

${ }^{52}$ Esta circunstancia revela que los tribunales asocian la falta de culpa con el caso fortuito y viceversa. Esta constatación resulta de suyo interesante habida cuenta de que 
A modo de ejemplo, puede citarse la sentencia de 17 de mayo de 2017 que establece que el MOP estaba en posición de prever las lluvias que ocurrirían en Concepción el año 2006, ocasionando el desborde del río Andalién y del estero Longuén y, a su vez, de adoptar las medidas que hubieran evitado que se inundara la ciudad. En circunstancias que las medidas adoptadas no eran aptas ni siquiera para contener las lluvias que en promedio se producían cada dos años ${ }^{53}$.

En cuanto a las medidas concretas a adoptar dependerá de una serie de factores, tales como el tipo de fenómeno natural de que se trate y las condiciones geográficas, topográficas y demográficas del lugar en que deben implementarse, así como de la rentabilidad social del proyecto ${ }^{54}$. En algunos casos, las medidas a implementar pueden, incluso, alcanzar la evitabilidad del fenómeno en sí mismo. Así, por ejemplo, los aludes pueden ser evitados reforestando las zonas de riesgos, construyendo piscinas decantadoras o, bien, reforzando el terreno. En otros, el fenómeno natural es en sí inevitable, como son: los terremotos, las lluvias, los tsunamis, las marejadas, la sequía, etc., con lo cual las medidas preventivas solo pueden apuntar a evitar sus consecuencias previsibles y evitables. En este sentido resulta destacable en especial la sentencia ya mencionada de 16 de noviembre de 2017, recaída en el caso conocido como "isla Mocha". En esta se constata la infracción de la autoridad en no haber educado y capacitado adecuadamente a la población a fin de que supiera cómo reaccionar frente a un terremoto de alta magnitud, lo que les privó de la posibilidad de ponerse a salvo por sus propios medios. Este razonamiento asume que en esas circunstancias no resulta exigible al Estado evitar el poder destructivo de un evento de esa naturaleza, pero ello no le exime de su obligación de educar a la población para que esta tenga las herramientas que le permitirían esquivar el daño por sus propios medios. La medida concreta a adoptar es, entonces, educar y capacitar a la población expuesta a ese tipo de fenómenos ${ }^{55}$.

Otro ejemplo claro lo proporciona la sentencia 19 de mayo de 2020, relativa a la inundación del centro de la ciudad de Punta Arenas el año

doctrinariamente el caso fortuito suele analizarse como una causal de interrupción del nexo causal. Los fallos, en cambio, demuestran que para los tribunales el caso fortuito excluye la culpa. Este argumento, sin embargo, excede los límites de este trabajo, con lo cual solo se dejará constancia de la verificación.

${ }_{53}^{53}$ Mario Quezada Silva y otros con Fisco de Chile (2017).

${ }^{54} \mathrm{Si}$ bien no se trata de una causa de responsabilidad, sino de un recurso de protección, para un análisis detallado de estos aspectos puede verse la sentencia que prohíbe a la Municipalidad de Antofagasta derribar los muros de contención de riesgo aluvional emplazados en esa ciudad con posterioridad al alud de 1991. Véase Marco Santander López con Municipalidad de Antofagasta (2017).

${ }^{55}$ Diodina Lefiqueo Pincheira con Fisco de Chile (2017). 
2012. En este caso, se condenó a la Onemi por no haber activado la alerta amarilla, como tampoco la alerta roja de emergencia, incumpliendo con la etapa preventiva del proceso de gestión del riesgo. Al efecto expresamente se lee:

"De las definiciones antes transcritas [de alerta amarilla y de alerta roja] fluye que ambas giran en torno al concepto de 'amenaza', esto es, un evento que todavía no se materializa y para cuyo enfrentamiento se requiere activar el mecanismo preventivo; en este caso, las alertas fueron decretadas una vez que el desborde ya había ocurrido, a pesar de que su carácter inminente podía preverse, toda vez que no fue discutido por las partes que el evento de precipitaciones inició la jornada anterior y, en consecuencia, tal finalidad previsora no fue cumplida" ${ }^{56}$.

Así las cosas, la etapa preventiva de la gestión del riesgo está intrínsecamente relacionada con la posibilidad de prever la ocurrencia del fenómeno natural, al igual que su intensidad. A su turno, atendida la gran cantidad de fenómenos naturales que históricamente han afectado al país, en Chile, esta cuestión se relaciona de forma directa con el registro histórico, tal como con la experiencia y capacidad técnica del demandado o sus auxiliares. En efecto, en la mencionada sentencia se lee:

"Que el estudio que sirvió de base al Plan Maestro de Evacuación y Drenaje de Aguas Lluvias de Punta Arenas, contempló un caudal de crecida de 137 metros cúbicos por segundo en el área de canalización, para un periodo de retorno de 100 años y de 71 metros cúbicos por segundo en un periodo de retorno de 10 años, consignando también distintas cantidades para los lapsos intermedios. Pues bien, la demandada ha alegado que en la parte baja de la ciudad precipitó $50,8 \mathrm{~mm}$, y en la parte alta de la cuenca precipitó 119,0 mm, sin embargo, ningún antecedente científico produjo o acompañó que permitiera al tribunal estimar que esa fue la medida de las precipitaciones y, en caso efectivo, que ellas excedían máximas históricas. Por el contrario, el fallo estableció que la demandada fue informada con la debida anticipación y por

${ }^{56}$ Rodrigo Araya Carreño y otros con Fisco de Chile y otros (2020). Un lectura semejante puede realizarse del fallo de 7 de enero de 2014, en que se condena a la Dirección de Vialidad por no haber adoptado las medidas preventivas para evitar la caída del puente Coinco sobre el río Cachapoal, a pesar de que las autoridades competentes habían decretado la alerta amarilla por precipitaciones, lo que causó la muerte de una persona. Véase Corina Solís Palominos y otros con Dirección de Vialidad (2014). 
el órgano técnico encargado, a través de avisos durante los días 9 , 10 y 11 de marzo informando de las precipitaciones continuas, así también lo aseveró el testigo el centro meteorológico señor Ibáñez, además de existir, en el Plan de Emergencia de la Región de Magallanes, antecedentes históricos sobre inundaciones y desbordes del río Las Minas en los años 1941 y 1990.

En consecuencia, si bien se trató de un nivel de precipitaciones poco frecuente, ello no significa ni así se acreditó, que sea imposible de prever, puesto que se contaba con todos los antecedentes técnicos para concluir que, al menos cada cierto número de décadas, es muy probable un evento de crecida de esta magnitud. A lo anterior se añade el hecho que sobre los organismos demandados pesa un deber general de previsión, con el objeto de evitar que se ocasionen a la población daños de manera recurrente, lo cual demanda que aquélla sea en un margen mayor y no igual a lo sucedido en periodos anteriores, puesto que precisamente aquello que se busca son medidas de carácter útil, idóneas y efectivas frente a sucesos superiores a los normales.

Por tanto, no es posible concluir que la crecida que generó los daños demandados, haya sido imprevisible" ${ }^{57}$.

Un razonamiento prácticamente idéntico se lee en la sentencia de 6 de marzo de 2013, relativa a la llamada "tragedia de Antuco", ocurrida el año 2005, la Corte Suprema resuelve:

"[...] no ha sido un hecho controvertido que el día de ocurrencia de los hechos, los conscriptos demandantes salieron en marcha al amanecer, que recorrieron varios kilómetros con el único inconveniente de que algunos se mojaron en un cruce de estero, que pudieron alcanzar algunos de los refugios existentes en la montaña; sin embargo, dadas las circunstancias de la marcha de repliegue, o sea, tratándose de una marcha inserta en un período de instrucción de conscriptos, jóvenes efectuando su servicio militar sin instrucción efectiva de montaña, en que se encuentran cuestionados por negligencia en el cumplimiento de sus deberes militares algunos de los soldados que componían la plana jerárquica encargada de dicha marcha; la probanza documental no es suficientemente clara y precisa en orden a determinar si efectivamente la producción del fenómeno fue un hecho desconocido, imposible de prever para quienes se encontraban al mando de los conscriptos y tomaban las

${ }^{57}$ Rodrigo Araya Carreño y otros con Fisco de Chile y otros (2020). 
decisiones por ellos, quienes debemos entender son expertos en instrucción de montaña y en el desarrollo de las marchas de este tipo, imposible de evitar para quienes lo soportaron; ya que de las probanzas rendidas no es posible necesariamente inferir que el viento blanco se hubiere producido de improviso dentro de la marcha, sin que pudiera evitarse sus consecuencias riesgosas, ya que el referido fenómeno climático era posible de aparecer en el lugar en que se encontraban y existían formas de mitigarlo, sin que se hubiere acreditado su utilización" 58 .

En resumen, el obligado a la gestión del riesgo constituido por el fenómeno natural está llamado a actuar antes de que el fenómeno se materialice, en todos aquellos casos en que su ocurrencia y/o sus consecuencias, puedan ser verosímilmente anticipadas, conforme a la experiencia y capacidad técnica ${ }^{59}$. Una cuestión distinta, pero que escapa a los objetivos de este texto, es el alto estándar de previsibilidad y resistibilidad que se impone a los demandados, en especial cuando se trata de organismos públicos, sobre todo en los últimos años.

En efecto, del análisis realizado es posible observar una evolución en la jurisprudencia nacional, en orden a la consideración de los fenómenos naturales como eventos previsibles e irresistibles. Así se observa al comparar las sentencias de la primera década de este siglo con las que se han dictado en años recientes, por ejemplo, a raíz de inundaciones. En las primeras se asumía que el evento climático consistente en lluvias extraordinarias constituía un caso fortuito, por ser imprevisible e irresistible ${ }^{60}$. En las más recientes, en cambio, se asume lo contrario. Esto es, que las precipitaciones, incluso de carácter extraordinario, son previsibles, pues se mira al registro histórico, al igual que los reportes de meteorología emitidos, incluso, con pocos días de anticipación ${ }^{61}$.

${ }^{58}$ Guillermo Claverie Bravo y otros con Fisco de Chile (2013).

${ }^{59}$ Esta idea se desprende con claridad de la sentencia de 29 de mayo de 2020, recaída en el caso conocido como "Casa-212", en que se condenó a la Fuerza Área "por haber designado una tripulación que carecía de la preparación, experiencia y aptitudes personales necesarias para enfrentar todos los distintos y posibles escenarios en que se puede desarrollar una misión”. Lo que determinó que los fuertes vientos en la zona ocasionara la caída de la aeronave dirigida a Juan Fernández. De esa manera, si bien el motivo concreto por el cual se produce la caída del avión radica en las condiciones meteorológicas adversas, ello no exime de responsabilidad a la demandada. Macarena Schuster Pinto y otros con Fisco de Chile (2020).

${ }^{60}$ V. gr. Luis Felipe Baeza Balbontín con Ilustre Municipalidad de Viña del Mar (2005)

y Carlos Vargas Alvarado contra Serviu Metropolitano (2010).

${ }^{61}$ V. gr. Ronald Pérez Flores con Viviendas 2000 Limitada (2016). 


\section{Responsabilidad derivada de una actuación del demandado}

Los fenómenos naturales no siempre son per se dañinos para las comunidades expuestas a ellos, pues estas están preparadas para soportar su ocurrencia. Sin embargo, puede ocurrir que un fenómeno en sí mismo inocuo dé origen a una situación de daño a raíz de la actuación de una persona que tiene la virtud de potenciar sus efectos nocivos. También puede ocurrir que un fenómeno per se apto para generar un daño de menor entidad termine generando daños mucho más graves o cuantiosos gracias a la intervención de la conducta humana, que exacerba su potencial dañino. En ambos casos, habrá lugar a la responsabilidad del agente potenciador del fenómeno, en la medida que su actuar resulte contrario al estándar de conducta que debía observar.

En la jurisprudencia nacional, especialmente destacables en este punto son las demandas por daños asociados a lluvias que, sumadas al hecho de que el demandado había intervenido el normal escurrimiento de las aguas, generan una inundación, un alud u otro evento dañino. Así, en la sentencia de 29 de mayo de 2012, se condena al dueño de un embalse recolector de aguas lluvias que había sido construido sin la autorización de la DGA, que al colapsar provocó la inundación de un predio vecino ${ }^{62}$.

Asimismo, en la sentencia de 21 de agosto de 2017, se condena a una empresa que había intervenido el cauce de la quebrada El Ñilhue, a través de movimientos de tierra y una construcción emplazada sin la autorización de la DGA, lo cual contribuyó a que se generara un alud de roca y barro que destruyó la casa del demandante, provocando la muerte de su cónyuge y la desaparición de su hija ${ }^{63}$.

En esta misma óptica, una situación digna de destacar especialmente es la que se produjo a raíz de la cancelación de la alerta de tsunami luego del terremoto de 27 de febrero de 2010. En particular, la comunicación radial emitida por el intendente de la Región del Biobío (en adelante Intendente) anunciando a la población la ausencia de riesgo de maremoto, el cual minutos más tarde se produciría ${ }^{64}$. Lo característico de estos casos es

${ }^{62}$ Luz Eliana Sandoval Rivera y otros con Muñoz Muñoz José Gabriel y otro (2012). En el mismo sentido, se condena a la empresa que realizó movimientos de acumulación de tierra, que luego dio lugar a que se inundara de barro la propiedad vecina. Véase Sociedad Pastelería Arraya Limitada con I. Municipalidad de Talcahuano y otro (2016). Véase también Luis Vergara Reyes y otros con I. Municipalidad de Concepción (2003) y Marta María Araya Muñoz con I. Municipalidad de Peñaflor (2007).

${ }^{63}$ Fernando Aspillaga Rodríguez con Héctor Sauvageot Torrecilla y otros (2017).

${ }^{64}$ Véase Juan Soto M con Fisco de Chile (2013); María del Carmen Valenzuela Flores y otros con Fisco de Chile (2013); Marta Adela Fonseca Vásquez con Fisco de Chile (2014); 
el hecho de que las víctimas no invocan una negligencia de las autoridades consistente en que no desplegaron las actividades que habrían permitido a la población ponerse a salvo, como sí hacen a propósito del tsunami en Juan Fernández, por ejemplo. Esta estrategia parece tener dos fundamentos. Por un lado, pretende resaltar la inoperancia de las autoridades que llegaron a cancelar la alerta de un tsunami que luego se produciría y, por otro lado, más jurídico, el hecho de que, atendido el conocimiento popular de las devastadoras consecuencias que anteriores terremotos produjeron en la zona, una alerta de tsunami en esas circunstancias no es necesaria para que la población se aleje de la costa o evite acercarse a ella, de suerte que lo contrario constituye una exposición imprudente al daño. En consecuencia, la causa del daño se asocia al "efecto tranquilizador" que el mensaje de la autoridad conllevaba. Se trata de lo que la doctrina conoce como la "causalidad psicológica". No se reprocha al Estado el haber materialmente causado el daño, sino haber inducido a la víctima directa a tomar una decisión perjudicial para sí misma ${ }^{65}$.

En efecto, atendida la magnitud del sismo y el conocimiento previo de la población del gran Concepción sobre las consecuencias de un sismo de esa intensidad, la comunidad era consciente de la importancia de alejarse, o permanecer alejado, de la costa. A su vez, la información oficial emitida por una autoridad descartando el peligro tiene (o cuando menos tenía en ese entonces) la virtud de infundir tranquilidad en la población. De manera que es posible realizar el siguiente juicio: de no haberse emitido por el Intendente la comunicación descartando la alerta de tsunami, es razonable suponer que la población se habría puesto a salvo alejándose de la costa o, bien, no acercándose a ella, lo contrario constituiría una exposición imprudente al daño.

Naturalmente, para que haya lugar a la causalidad psicológica es necesario que el mensaje del inductor efectivamente llegue al inducido. Aplicado a este caso, ello significa que, para que configure la responsabilidad para el Intendente (el fisco) la víctima debió haber tenido noticia de la comunicación y la decisión de permanecer o acercarse a la costa debió haber sido motivada por esa noticia, aspecto que debe estar acreditado,

Luis Salgado Delgado y otro con Fisco de Chile (2014); Alejandro Moscoso Larenas con Fisco de Chile (2016); Elías Cifuentes Sánchez y otros con Fisco de Chile (2017); Gabriela Sepúlveda Aliste con Fisco de Chile (2017); Luis Mella Guzmán y otros con Fisco de Chile (2018); Norma Silva Hidalgo con Fisco de Chile (2018); Marioly Gatica Valdebenito y otros con Fisco de Chile (2019) y Carolina Luna Miranda con Fisco de Chile (2018).

${ }^{65}$ En palabras de Tony Honoré, "lo que queremos decir cuando hablamos de 'inducir', 'persuadir', etc., es hacer referencia a las razones que a esta persona le parecieron adecuadas en esta ocasión y, por lo tanto, sobre la base de las cuales actuó”. Cfr. HonORÉ (2013), p. 1095. En este caso, las razones que llevaron a los fallecidos a permanecer en su domicilio en lugar de desplazarse a las zonas altas de la ciudad. 
como es debido, en el juicio. Así justamente se han resuelto estos casos en la jurisprudencia, pues los tribunales han desechado demandas en que está acreditado que la decisión de las víctimas de acercarse a la costa fue anterior al comunicado del Intendente. Asimismo, se han desechado demandas en que, a pesar de que la decisión de la víctima es posterior al anuncio, no está acreditado que lo haya escuchado o haya tenido noticia del mismo. Mientras que se han acogido aquellas en que se ha tenido por probado que la víctima tuvo noticia del anuncio.

\section{LA INCERTIDUMBRE CAUSAL ASOCIADA A LOS DAÑOS DERIVADOS DE FENÓMENOS NATURALES}

Como se señaló para que haya lugar a la responsabilidad civil por daños ocasionados por fenómenos naturales es necesario que la víctima acredite una de estas dos circunstancias:

i) que el demandado estaba obligado a actuar a fin de impedir que el fenómeno natural se transformara en un daño o

ii) que el fenómeno natural en sí mismo habría sido inocuo o, bien, habría causado un daño menor, pero se transformó en dañino debido a la actuación imputable del demandado.

En ambos casos, se trata de establecer la relación de causalidad entre la inactividad o actuación del demandado y el daño sufrido por la víctima, para lo cual esta debe solventar la carga de la prueba ${ }^{66}$. De esta manera, si no se logra el estándar de prueba exigido por el ordenamiento respectivo, la demanda deberá ser rechazada ${ }^{67}$.

${ }^{66}$ Los tribunales han reconocido que esta carga puede solventarse por cualquiera de los medios de prueba reconocidos por el ordenamiento. Así se resolvió en un caso en que el demandado alegaba que la erosión del suelo provocada supuestamente por la tala de árboles que él había realizado, debía ser probada por peritos y no por testigos, como en los hechos se hizo. La Corte Suprema resolvió "que esta alegación carece de apoyo legal, toda vez que no existe en nuestro ordenamiento jurídico alguna prohibición respecto de la procedencia de la prueba de testigos para acreditar hechos como los discutidos en estos autos”. Cfr. María Soledad Manríquez Aravena con Fisco de Chile (2008).

${ }^{67}$ Claro en este sentido es el fallo de 22 de mayo de 2013, en que se exonera de responsabilidad a la Concesionaria Ruta de los Ríos, fundándose en el hecho de "que si bien en el lugar del accidente en condiciones climáticas de lluvia se produce acumulación de agua en la zona central de la carretera, la que escurre sobre ella hacia el costado, esa sola circunstancia es insuficiente para establecer la relación de causalidad con el resultado dañoso, desde que los vehículos que se ven transitando por allí no pierden la estabilidad ni se produce algún accidente atribuible a esa causa". Cfr. Sandra Margoth Vidal y otros con Ruta de los Ríos Sociedad Concesionaria y otro (2013). Véase también Iván Espíndola Canelo y otra con Gloria Arbulo Núñez y otros (2016). 
Ahora bien, en Chile, se afirma que, para que haya lugar a responsabilidad, debe estar probado que la conducta diligente del demandado, "con verosimilitud rayana", habría evitado el daño ${ }^{68}$. Así las cosas, el estándar de prueba civil es alto, cercano a la certeza ${ }^{69}$. Esto resulta en especial complejo cuando se trata de daños asociados a fenómenos naturales, pues, dado que este tipo de fenómenos se produce sin la intervención o de forma independiente de la voluntad humana, la conducta del demandado es solo una de las condiciones necesarias para la producción del daño. El fenómeno natural es, por tanto, otra condición necesaria o sine qua non del daño: eliminado mentalmente el fenómeno el daño no se habría producido. Esta circunstancia determina que la responsabilidad civil derivada de fenómenos naturales se caracterice por una elevada incertidumbre causal que, sumada al alto estándar de prueba reconocido en el ordenamiento nacional, determina que la víctima tenga escasas probabilidades de obtener una sentencia favorable.

Con todo, en los últimos años, es posible observar que tal razonamiento ha sido morigerado por la jurisprudencia a través de diversas estrategias ${ }^{70}$, tales como tener por acreditado el nexo causal a través de presunciones judiciales ${ }^{71}$, rebajar el estándar probatorio de la causalidad sobre la base de las circunstancias del caso $^{72}$ y aceptar una responsabilidad proporcional sobre la base de la pérdida de oportunidad ${ }^{73}$.

En esta sede, cabe sobre todo destacar este último aspecto, pues, justo al alero de esta doctrina se han resuelto los casos con mayor incertidumbre causal. La cual deriva del hecho de que no es posible establecer si la correcta actuación por parte del demandado (en concreto instituciones

${ }^{68}$ Araya (2003), p. 65.

${ }^{69}$ Sobre los estándares de prueba y su aplicación por la jurisprudencia civil chilena, véase Larroucau (2012), pp. 783-80 y LaRrocau (2014), pp. 43-79.

${ }^{70}$ Ampliamente sobre este argumento, San Martín y Larroucau (2020), passim.

${ }^{71}$ Esta fórmula fue utilizada en los casos del $27 \mathrm{~F}$ en que se discutía si efectivamente las víctimas habían escuchado el anuncio radial del intendente del Biobío, aspecto indispensable para establecer que este anuncio había sido determinante en la decisión de las víctimas de no ponerse a salvo de un posible tsunami. V. gr. María del Carmen Valenzuela Flores y otros con Fisco de Chile (2013), un análisis de este caso puede verse en San Martín (2013), pp. 297-308 y Lara y García-Huidobro (2014), pp. 163-194.

${ }^{72}$ En la misma sentencia recién citada la Corte Suprema realiza una expresa declaración en este sentido, toda vez que señala: “[...] es el parecer de esta Corte que no se aviene con el sentido común extremar la carga probatoria en circunstancias tan caóticas como las que -conocimiento adquirido- sucedieron a las catástrofes, como si entonces estuvieran dadas las condiciones para documentación burocrática propia de tiempos normales". Cfr. María del Carmen Valenzuela Flores y otros con Fisco de Chile (2013).

${ }^{73}$ Sobre esta teoría y su planteamiento den la doctrina nacional, por todos: Ríos y Silva (2014); Barría (2019), pp. 235-269 y Mejías (2019), p. 1067 y ss. 
estatales) habría evitado el deceso de numerosas víctimas del tsunami de $2010^{74}$. En estos casos, sin embargo, como señala Rodrigo Barría, no necesariamente se respetan los presupuestos y resultados de dicha teoría, los que terminan por forzarse a fin de encuadrar en ella tales $\operatorname{casos}^{75}$. En particular, los fallos no se detienen a analizar si hubo una real oportunidad perdida, así como tampoco fijan la cuantía de la indemnización conforme a la idea de proporcionalidad, sino que fijan una indemnización en globo, que es más bien la reparación integral del daño sufrido por los demandantes a raíz del fallecimiento de sus seres queridos.

Sin perjuicio de que escapa al objetivo de este trabajo, resulta oportuno señalar que la flexibilización del requisito de la prueba de la causalidad en casos de daños ocasionados por fenómenos naturales, en especial la forma en que ha sido aplicada la doctrina de la pérdida de oportunidad, se explica a la perfección cuando se tiene a la vista que, a diferencia de otros países igualmente propensos a desastres naturales ${ }^{76}$, en Chile no existe un sistema de seguros destinado cubrir los daños ocasionados por estos eventos. De esta manera, la indemnización a título de responsabilidad civil es la única forma de dejar indemnes a víctimas que de otra forma no habrían obtenido reparación alguna. Todo lo cual deja entrever una suerte de función asistencial o social de la responsabilidad en este tipo de ca$168 \operatorname{sos}^{77}$.

\section{LA EXTENSIÓN DE LA INDEMNIZACIÓN: \\ AUSENCIA DE FRACCIONAMIENTO DE LA INDEMNIZACIÓN FUNDADA EN EL APORTE CAUSAL DEL FENÓMENO NATURAL}

Atendido que los fenómenos naturales son conditio sine qua non del daño al que alude este trabajo, resulta lícito preguntarse si cabe invocar este hecho como una concausa apta para reducir la indemnización solicitada.

${ }^{74}$ V. gr. Diodina Lefiqueo Pincheira con Fisco de Chile (2017); René Pinto Flores y otros con Fisco de Chile (2018); Víctor Arriagada Sepúlveda y otros con Fisco de Chile (2018) y Ángel Sepúlveda Sepúlveda con Fisco de Chile (2019).

${ }^{75}$ BARria (2019), p. 264 y ss.

${ }^{76}$ Por ejemplo, en España (Consorcio Compensación de Seguros: www.consorseguros. es), Nueva Zelandia (EQC: www.eqc.govt.nz) y Francia (CCR: www.ccr.fr/index.do), existen organismos creados para la gestión de daños extraordinarios que, en síntesis, actúan como aseguradoras para determinados riesgos, entre los cuales se incluyen desastres naturales tales como, terremotos, erupciones, inundaciones, etc. Algo similar ocurre en Japón, que posee un sistema de reaseguro estatal para terremotos -JERC. Un resumen de la regulación jurídica en torno a los desastres en Japón, incluido el sistema de seguros, puede verse en Jaramillo (2012), p. 11 y ss.-.

${ }^{77}$ Ampliamente sobre este tema SAN MArTín (2020), passim. 
$\mathrm{Al}$ respecto, cabe señalar que hay dos formas de entender esta concurrencia causal. Una en que el fenómeno natural concurre con la conducta del demandado para producir un único daño indivisible y otra en que el fenómeno natural es por sí mismo apto para producir el mismo tipo de daño, solo que en menor intensidad. Desde luego, esto supone que se trate de un daño divisible o fraccionable.

En el primer caso, la solución que parece imponerse es que la conducta humana imputable absorbe la condición natural, en la medida que un verdadero concurso de causas solo puede producirse entre conductas humanas culpables ${ }^{78}$. Este parece ser el entendimiento de la Corte Suprema en el fallo de 7 de junio de 2016, recaído en un caso de ausencia de alerta de tsunami, en el cual afirmó:

"Que lo anterior permite descartar la alegación del Fisco de Chile en torno a la ausencia de vínculo de causalidad entre la falta de servicio alegada y la muerte de Erices Oñate. En efecto, si ella hubiera recibido oportunamente la alerta de maremoto hubiera dispuesto del tiempo suficiente para alcanzar la zona de seguridad. Es cierto que estamos frente a un efecto dañoso producido por concausas; un hecho de la naturaleza que corre paralelamente con la tardía reacción de los organismos creados para enfrentar los desastres naturales. Ambas son causas directas y necesarias del daño producido, por lo que no sólo se verifica una constatación física de causalidad, sino que además hay una constatación jurídica de que dicho daño le es imputable al demandado"79.

La misma idea se desprende de la sentencia de 21 de agosto de 2017, en que se demanda por la muerte de dos personas ocurrida a raíz de un alud en cuya producción y magnitud contribuyó la conducta de los demandados. En este caso, los tribunales resuelven:

"La construcción ejecutada no fue la única causa del aluvión, pero contribuyó a la magnitud alcanzada por éste, al impedir el libre escurrimiento de aguas cuyo caudal ya era superior al normal, aumentando el alud con gran parte de la construcción del terraplén"80.

${ }^{78}$ Esto sería una consecuencia del hecho de que la culpa desde antiguo es justamente un criterio de selección de las condiciones jurídicamente relevantes. De modo que, existiendo una condición culpable y otra natural, solo la primera se considera "la causa" del daño. Sobre el particular, véase Aedo (2015), pp. 37-75 y SAn Martín (2018), p. 54 y ss.

${ }^{79}$ Alba Oñate Sanhueza con Fisco de Chile (2016).

${ }^{80}$ Fernando Aspillaga Rodríguez con Héctor Sauvageot Torrecilla y otros (2017). 
Sin embargo, cabe reconocer que, más allá de estas consideraciones, que tienen más bien el carácter de obiter dicta, la cuestión no ha sido abordada por los tribunales nacionales. Por lo demás, se trata de un asunto bastante discutible. De esta manera lo demuestra el hecho de que en el extranjero se haya planteado en más de una ocasión el mismo problema. En consecuencia, merece un tratamiento teórico más profundo, que excede a los propósitos de este texto ${ }^{81}$.

En cuanto concierne al segundo grupo de casos, esto es, aquellos en que el fenómeno natural es por sí mismo apto para generar uno o más daños, que se ven multiplicados o intensificados por la conducta del demandado, no parece haber inconvenientes en aceptar que la indemnización deba adecuarse conforme a la contribución causal de la actividad del demandado. Tal solución encuentra apoyo en el principio de reparación integral del daño, en virtud del cual la víctima no puede traspasar al agente los riesgos que ella estaba llamada a soportar, incluso, sin la intervención de este. En consecuencia, el agente solo es obligado a indemnizar los daños que le resulten imputables desde el ámbito jurídico y no aquellos que la víctima habría padecido de todas maneras.

En todo caso, tampoco se observan mayores consideraciones sobre el particular en la jurisprudencia chilena, que omite cualquier reflexión en presencia una multiplicidad de partidas indemnizatorias, así como en presencia de daños típicamente divisibles o fraccionables, como son los daños patrimoniales o, bien, daños morales derivados de pérdidas patrimoniales y afectaciones que, aunque en menor medida, igualmente se habrían producido. Así, la jurisprudencia simplemente niega la indemnización o, bien, la concede de forma integral.

En tal sentido es posible observar los casos relativos a demandas por defectos en la construcción en relación con el terremoto de 2010. Como es sabido, un terremoto de magnitud 8.8 es per se apto para ocasionar daños en las construcciones, incluso si ellas han sido erigidas conforme a la lex artis. De esta manera, se plantea la posibilidad de que los defectos en la construcción aumenten la magnitud de los daños que en cualquier caso se habrían producido con ocasión del terremoto. Sin embargo, las sentencias dictadas al respecto, acogen o rechazan la demanda, pero no hay pronunciamientos en orden a una indemnización parcial de los daños lamentados por el demandante ${ }^{82}$.

${ }^{81}$ Algunas consideraciones sobre el particular en SAN MARTín (2019), p. 132 y ss.

${ }^{82}$ V. gr. Comunidad Edificio Don Roberto con Inmobiliaria e Inversiones Mitras Corp Limitada (2013); Corporación Administrativa del Poder Judicial con Sergio Eduardo Morales Ibarra (2015); Corporación Administrativa del Poder Judicial con Conservación y Mantención de Edificios Limitada (2016); Sergio Eduardo Ortiz Troncoso con Inmobiliaria Don Cristóbal S.A. (2016); Luisa Torres Puentes y otro con I. Municipalidad de Talcahuano 
Otro caso ejemplificador es el fallo de 19 de mayo de 2020, relativo a la inundación de la ciudad de Punta Arenas el año 2012. Este, reproduciendo lo resuelto por los tribunales de instancia, afirma:

"[...] de haber mediado por parte de ellos [la Municipalidad y la ONEMI] una actuación oportuna y eficiente, dando aviso a la población a través del sistema de alertas que contempla en Plan de Protección Civil, empezando por instar a que se decretara alerta temprana, la crecida del Río habría generado un daño controlado, pues habría permitido la preparación de los demandados frente al riesgo cierto de inundación, minimizando la pérdida de sus bienes, los habría predispuesto a afrontar una situación extrema excluyendo la sorpresa y minimizando el impacto sicológico al ver en peligro su integridad física y la de sus familiares" ${ }^{\$ 3}$.

Es decir, los tribunales reconocen que la conducta diligente de los demandados no habría evitado la inundación, sino, que solo habría dado a las víctimas la posibilidad de morigerar sus pérdidas y prepararse psicológicamente para lo inevitable. Sin embargo, y sin perjuicio de esa afirmación, la Corte condena a la Onemi y a la Municipalidad del Punta Arenas al resarcimiento integral del daño.

La explicación para esta circunstancia pareciera encantarse en el hecho de que los fenómenos naturales se invocan bajo la excepción de caso fortuito, la cual da lugar a una defensa 'todo o nada' y, por tanto, se acoge o se rechaza la demanda ${ }^{84}$. Paradigmático en este sentido es el fallo de Corte Suprema de 17 de julio de 2019. En este caso, los tribunales de instancia consideraron que, al existir una parte indeterminada de los daños provocada por el sismo, es imposible cuantificar los daños indemnizables, en consecuencia, corresponde rechazar la demanda en su totalidad. Ello más allá de que el mismo informe pericial señale que existen defectos de construcción y que estos son parte de los factores que originan el daño. La Corte Suprema, por su parte, casa la sentencia señalando:

(2016); Adil Brkovic Almonte con Inmobiliaria Armas Capital Limitada (2016); Percy Harold Cepeda Martignoni con José Gabriel Alemparte Rojas y otros (2016); Ronald Pérez Flores con Viviendas 2000 Limitada (2016); Fabián Bastías Olea y otros con Fisco de Chile y otro (2017); Vladimir Cáceres Vergara con Inmobiliaria San Pedro del Valle S.A. y otros (2017); Universidad de Talca con Constructora Marcelo Rivano Limitada (2919) y Cristián Sánchez Díaz y otros con Inmobiliaria Miramar Limitada y otro (2019).

${ }^{83}$ Rodrigo Araya Carreño y otros con Fisco de Chile y otros (2020).

${ }^{84}$ Así ha sido tradicionalmente entendido por la doctrina y jurisprudencia nacional, véase SAn MARTín (2019), p. 54 y ss. 
"lo anterior vulnera los artículos 45 y 1547 del Código Civil, puesto que determina, en definitiva, que, a pesar de existir culpa por parte de la demandada, ésta viene aminorada o atenuada por el terremoto, y siendo imposible determinar el grado en que ello ocurriría, no da lugar a indemnización alguna. Lo anterior no coincide con la interpretación que debe darse al caso fortuito y particularmente, a la circunstancia de concurrencia de la culpa del deudor y de un suceso de esta naturaleza. En efecto, el caso fortuito debe ser considerado siempre desde una perspectiva de ajenidad: bajo ningún respecto puede considerarse que haya caso fortuito si el deudor, de alguna forma, ha contribuido a la creación del riesgo implícito. Lo anterior implica que, en este caso concreto, al haber efectuado la construcción de manera defectuosa, según el informe pericial, no correspondía que se determinara que parte de los daños eran causados por un caso fortuito, y por lo tanto, se infringieron las normas antes señaladas" ${ }^{85}$.

Adicionalmente, como una ulterior explicación para la ausencia de consideraciones jurisprudenciales en torno al tema, está el hecho de que los demandados no invocan, ni siquiera en forma subsidiaria, la contribu172 ción parcial del fenómeno natural en la producción del daño, sino que se limitan a oponer la excepción de caso fortuito. Así las cosas, los tribunales no pueden sino absolver o condenar por el total, pues una decisión distinta comportaría una hipótesis de extra petita.

VI. FENÓMENOS NATURALES Y FUNCIÓN PREVENTIVA DE LA RESPONSABILIDAD CIVIL. LA POSIBILIDAD DE EJERCER LA ACCIÓN DE DAÑO CONTINGENTE PARA PREVENIR QUE LOS FENÓMENOS NATURALES SE TRANSFORMEN EN DAÑOS

El último punto a tratar en esta sede es la función preventiva de la responsabilidad civil y la posibilidad de ejercer acciones que persigan, con anterioridad a la ocurrencia del fenómeno natural, la responsabilidad de quien está obligado a la gestión del riesgo. Esta forma de enfrentar el problema resulta de toda lógica cuando se considera que el fenómeno natural puede ser inevitable, pero no necesariamente lo son sus consecuencias. En efecto, como se dijo al inicio de este texto, la nocividad de un fenómeno natural no depende de su intensidad, sino del nivel de exposición al mismo, lo que se conoce como "vulnerabilidades". De esta manera, la adopción de medidas de mitigación tendientes a reducir la

${ }^{85}$ Universidad de Talca con Constructora Marcelo Rivano Limitada (2019). 
exposición o vulnerabilidad es fundamental en la etapa preventiva de la gestión del riesgo ${ }^{86}$.

En lo que respecta a la responsabilidad civil, en el ordenamiento jurídico chileno esta cuestión se relaciona especialmente con la acción de daño contingente contemplada en el art. 2333 del $C C^{87}$. En efecto, esta herramienta es de suyo apto para imponer al encargado de la gestión del riesgo que desarrolle las actividades preventivas en orden a impedir que, frente a la verificación de un fenómeno natural, se genere un daño que él está en posición de evitar ${ }^{88}$. No obstante, es del caso resaltar que existe escasa jurisprudencia en tal sentido.

Como excepciones al panorama anterior, cabe señalar que de manera puntual se ha ejercido la acción de daño contingente para prevenir que situaciones de daño asociadas a fenómenos naturales, ya producidas, se reiteren, incluso de manera más grave. Este es el caso de los fallos de Corte de Apelaciones de Santiago, de 15 de febrero de $2015^{89}$ y del $2^{\circ}$ Juzgado Civil de Talcahuano, de 28 de febrero de $2018^{90}$.

En el primero, se demanda a los responsables de una viña cuyas quemas controladas, realizadas con materiales neumáticos y otros materiales sintéticos, contribuyeron a potenciar la escasa visibilidad ocasionada por la densa niebla que cubría la ruta 68 a la altura de Casablanca, provocando una colisión múltiple de cincuenta vehículos el 12 de octubre de 2011. En la

${ }^{86}$ Nivolianitou (2002), pp. 161-174; Ríos (2010), pp. 27-43; Doyle et al. (2014), pp. 75101 y SAntini (2015), p. 48 y ss.

${ }^{87} \mathrm{Al}$ margen de la responsabilidad civil, otro conjunto de herramientas útiles para gestionar en forma preventiva el riesgo derivado de los fenómenos naturales son las llamadas acciones posesorias especiales, específicamente la denuncia de obra ruinosa. En efecto, este instituto tiene como objetivo evitar el daño temido (damnum infectum), aun en presencia de fenómenos naturales. Así se desprende de manera explícita del art. $934 \mathrm{del} C C$. Todo lo cual resulta en especial relevante en un país muy sísmico como Chile, donde una construcción en mal estado puede fácilmente caer producto de un sismo, incluso de mediana intensidad. Desde luego, en sede de derecho público, otra herramienta de gran utilidad es el recurso de protección - v. gr. Marco Santander López con Municipalidad de Antofagasta (2017) y José Venegas Toro con Municipalidad de Antofagasta (2017)-. El recurso de protección tiene una clara ventaja, que es la celeridad. Sin embargo, las herramientas civiles tienen también tienen importantes puntos a favor: en primer lugar, no es necesario encuadrar la conducta del demandado en una acción arbitraria o ilegal, sino que basta con probar una actitud negligente o imprudente que razonablemente amenaza con transformarse en un daño; en segundo lugar, ellas no están sujetas a plazo de prescripción, pues perviven mientras dure el peligro que se pretende conjurar.

${ }^{88}$ Para algunas reflexiones sobre este tema véase SAN MARTín (2019), p. 135 y ss.

${ }^{89}$ Sociedad Concesionaria Rutas del Pacífico S.A. con Sociedad Agrícola ARC Holding Ltda. y otros (2015).

${ }^{90}$ Bárbara Ivanschitz Boudeguer y otros con Constructora Kuden SPA (2018). Confirmada por Bárbara Ivanschitz Boudeguer y otros con Constructora Kuden SPA (2019). 
causa se ejerce la acción del art. 2333 a fin de que los demandados adopten medidas tendientes a mitigar los riesgos de que un acontecimiento de ese tipo se repita. La Corte de Apelaciones de Santiago, revocando la sentencia de primera instancia, condenó a la demanda en los siguientes términos:

" $1^{\circ}$ Se prohíbe todo tipo de acto que implique la quema de cualquier material vegetal, sintético y/o plástico en el predio denominado Paso Tapihue, como mecanismo para regular la temperatura en los viñedos del inmueble, sin perjuicio del ejercicio de los derechos que la legislación vigente reconoce en el Decreto Ley $\mathrm{N}^{\circ} 276$, de 1980, del Ministerio de Agricultura. // $2^{\circ}$ - Comunicar y registrar ante la autoridad competente -CONAF- y asimismo informar a la demandante, con la anticipación necesaria, la decisión de efectuar 'quemas controladas' en el Predio de que se trata, cumpliendo para ello con las formalidades del Decreto Ley $\mathrm{N}^{\circ} 276$, de 1980, del Ministerio de Agricultura; // $3^{\circ}$.- Se condena a los demandados a pagar las costas de la causa, las que se dividirán en partes iguales" ${ }^{\prime 1}$.

En el segundo caso, se demanda a una constructora que había realizado movimientos de tierra, producto de los cuales, a raíz de las copiosas lluvias que caen en la ciudad de Concepción, se habían generado deslizamientos de agua y barro hacia su casa. El afectado ejerce la acción del art. 2333 para que la constructora adopte las medidas tendientes a evitar que estos sucesos en el futuro se repitan y/o agraven. La demanda es acogida en los siguientes términos:

"[...] se ordena a la demandada adoptar las siguientes medidas para evitar la producción del daño: // a) Demoler el muro ubicado al norte del área verde que marca el límite septentrional del inmueble de la actora ya individualizado en autos. // b) Construir un muro de contención en dicho lugar, debidamente diseñado y calculado por el responsable del proyecto, el cual deberá adoptar todas las medidas legales y técnicas en lo que se refiere a la construcción de muros de contención, debiendo aumentar la cota del mismo 50 centímetros de la ya existente. En dicha construcción se deberá efectuar una revisión completa del sistema de drenaje del muro, el cual deberá ajustarse a la normativa técnica vigente en nuestro país. // c) Revisar el sistema de recolección de aguas para que este se ajuste y se encuentre acorde a lo que se encuentra en los pro-

${ }^{91}$ Sociedad Concesionaria Rutas del Pacífico S.A. con Sociedad Agrícola ARC Holding Ltda. y otros (2015). 
yectos respectivos que sustentaron la entrega del permiso de obra nueva $N^{\circ} 99$ de la Dirección de Obras Municipales de la Municipalidad de Chiguayante. // d) Proteger y estabilizar el talud existente por medio de protección de cubierta vegetal o artificial que asegure que no se produzcan escurrimientos de aguas al predio de la actora, así como no se generen deslizamientos de tierras en la misma dirección. // 2. Que para las medidas que anteceden de fija un plazo de treinta días corridos en los cuales éstas deberán estar adoptadas y terminadas. // 3. Que el demandante deberá pagar a la actora lo que valga el tiempo y diligencias empleados en la acción interpuesta, reservándose su determinación para la etapa de cumplimiento del fallo" 92 .

En síntesis, aunque de manera incipiente y asociada a eventos ya acaecidos, se observa la utilidad de la acción por daño contingente para prevenir daños asociados a fenómenos naturales, en aquellos casos en que la actividad imprudente o negligente de un sujeto implique potenciar el riesgo propio del fenómeno.

\section{CONCLusiones}

La revisión jurisprudencial realizada en este texto da claramente cuenta de que los fenómenos naturales han dejado de pertenecer per se al ámbito del caso fortuito, para entrar de lleno en el de la responsabilidad civil. Así lo demuestra la gran cantidad de demandas por daños derivados de este tipo de acontecimientos.

Esa responsabilidad recae en el sujeto jurídicamente obligado a la gestión del riesgo de desastre, el cual puede ser una persona jurídica de derecho público o, bien, un particular. En el primer caso, se trata de la responsabilidad del Estado por falta de servicio, en el segundo, de la responsabilidad extracontractual entre particulares. Con todo, en el análisis jurisprudencial no se aprecian mayores diferenciaciones entre ambos regímenes, toda vez que en ambos casos la responsabilidad se construye sobre la base de la infracción a un deber de cuidado. Esta infracción puede deberse a una omisión, en cuyo caso los tribunales realizan el esfuerzo de identificar la fuente del deber jurídico de actuación, así como a una acción imprudente o negligente, en cuyo caso la culpa (o falta de servicio) se construye sobre la base de la comparación entre el comportamiento de una persona (o servicio) razonable y lo que efectivamente hizo el demandado.

${ }^{92}$ Bárbara Ivanschitz Boudeguer y otros con Constructora Kuden SPA (2018). 
La gestión del riesgo de desastre es un proceso complejo, compuesto de varias etapas, entre las que destacan las fases preventivas, esto es, antes de la ocurrencia del fenómeno natural, y la gestión de la emergencia una vez que el evento ya ha acaecido. Las sentencias analizadas imponen responsabilidad por una infracción al deber de cuidado en cualquiera de estas etapas. De modo que, en algunas ocasiones, se condena por no haber adoptado medidas preventivas que habrían evitado la concreción de la amenaza de daño que comporta el fenómeno natural. Mientras que en otros casos se condena por no haber reaccionado (por acción u omisión) conforme las exigencias del deber de cuidado que pesaba sobre el demandado.

Además de la infracción al deber de cuidado, para que haya lugar a la responsabilidad civil por este tipo de daños, debe quedar acreditado en el proceso que, a pesar del fenómeno natural, el daño no se habría producido -cuando menos no en la intensidad verificada- si el demandado hubiese observado adecuadamente su deber de gestión del riesgo. En otras palabras, debe estar probado el nexo de causalidad entre el daño y la conducta del demandado, quedando el riesgo de falta de prueba de cargo de la víctima, conforme a las reglas generales en la materia. Esta circunstancia es en particular apremiante, pues tanto la conducta humana como el fenómeno natural son condiciones necesarias del daño, lo cual comporta que estos casos se caractericen por un elevado grado de incertidumbre causal, que llevaría a desestimar la mayor parte de las demandas. Sin embargo, en la jurisprudencia analizada se aprecia una clara tendencia a favorecer a las víctimas de estos acontecimientos, a través de diversas estrategias. En concreto, se tiene por probado el nexo causal a través de presunciones, se rebaja el estándar de prueba en atención a las circunstancias extremas en que se genera el daño y, la más difusa de todas las estrategias, se aplica la doctrina de pérdida de la chance para aquellos casos en que no es posible establecer si efectivamente la actitud correcta del demandado habría salvado a la víctima.

Otro aspecto que revela el análisis jurisprudencial es el nulo reconocimiento al problema de la concurrencia de causas en la producción del daño. Este análisis está ausente tanto en lo que respecta a la posibilidad de establecer una concurrencia causal entre el fenómeno natural y la conducta del demandado cuando se genera un daño único e indivisible, como cuando se trata de una multiplicidad de daños o, bien, de un único daño divisible o fraccionable. En ambos casos, una vez establecida la responsabilidad del demandado, los tribunales conceden la indemnización integral del daño padecido por la víctima, sin excluir aquellos daños que la víctima habría en cualquier caso sufrido producto del fenómeno natural. 
Finalmente, una última cuestión que revela el análisis, es el reconocimiento de parte de los tribunales de la posibilidad de hacer efectiva la etapa preventiva de la gestión del riesgo a través de la acción de daño contingente del art. $2333 \mathrm{del} C C$. Si bien de manera incipiente, es posible encontrar jurisprudencia al respecto.

\section{BibLiografía CITADA}

AA. VV. (2018). WeltRisikoBericht 2018. Disponible en www.welthungerhilfe.de/ fileadmin/pictures/publications/de/studies-analysis/2018-WeltRisikoBericht2018_BEH-final.pdf [fecha de consulta: 1 de octubre de 2020].

Aedo Barrena, Cristian (2015). "La cuestión causal en la "lex Aquilia" y su solución mediante el mecanismo de la culpa". Revista de Estudios Histórico-Jurídicos, n. ${ }^{\circ}$ XxxviI. Valparaíso.

Alarcón González, Victoria Andrea y Francisca Isidora Muñoz Bruna (2018). Análisis jurisprudencial sobre la responsabilidad civil extracontractual del estado por falta de servicio derivada del terremoto y posterior tsunami del 27F. Memoria para optar al grado de Licenciada en Ciencias Jurídicas y Sociales. Santiago: Universidad de Chile. Facultad de Derecho. No publicada.

Araya Jasma, Fernando (2003). La relación de causalidad en la responsabilidad civil. Santiago: Editorial Lexis Nexis.

BARRÍA DÍAZ, Rodrigo (2019). "La pérdida de una oportunidad en la jurisprudencia de la corte suprema sobre juicios indemnizatorios derivados del terremoto y tsunami de 27 de febrero de 2010". Revista de Derecho. Universidad de Concecpción, n. $^{\circ} 245$. Concepción.

Binder, Denis (1996). "Act of God? or Act of Man?: A Reappraisal of the Act of God Defense in Tort Law". The Review of Litigation, No. 15, vol. 1. Disponible en https://papers.ssrn.com/sol3/papers.cfm?abstract_id=821414 [fecha de consulta: 1 de octubre de 2020].

Corral Talciani, Hernán (2010). "Responsabilidad civil en la construcción de viviendas. Reflexiones sobre los regímenes legales aplicables a los daños provocados por el terremoto del 27 de febrero de 2010". Revista Chilena de Derecho, vol. 37 , n. 3 . Santiago.

Doyle, Emma, John Mc Clureb, Douglas Patonc \& David M. Johnstonad (2014). "Uncertainty and decision making: Volcanic crisis scenarios". International Journal of Disaster Risk Reduction, No. 10. London.

Farfarello Galletti, Antonella (2019). Responsabilidad del Estado. Terremoto del 27 de febrero de 2010. Santiago: Rubicón Editores.

GuERrA, Ignacio, (2019). "Video: La tranquilidad de pasajeros chilenos en el aeropuerto de Santiago ante el temblor de la que hablan en el mundo". Emol, 30 de septiembre de 2019. Disponible en www.emol.com/noticias/Nacio- 
nal/2019/09/30/962661/Tranquilidad-chilenos-aeropuerto-Santiago-temblor. html [fecha de consulta: 1 de octubre de 2020].

Hassol, Susan Joy, Simon Torok, Sophie Lewis y Patrick Luganda (2016). "Desastres (no) naturales: cómo comunicar los vínculos entre los fenómenos extremos y el cambio climático". Boletín de la OMM, vol. 65, n. ${ }^{\circ}$ 2. Disponible en https://repositorio.aemet.es/bitstream/20.500.11765/7289/1/Bo1OMM_65_2\%20\%281\%29.pdf [fecha de consulta: 16 de septiembre de 2020].

Henríquez, Cristián, Nicolle Aspee y Jorge Quense (2016). "Zonas de catástrofe por eventos hidrometereológicos en Chile y aportes para un índice de riesgo climático". Revista de Geografía Norte Grande, n. ${ }^{\circ}$ 63. Santiago.

Honoré, Tony (2013). "Condiciones necesarias y suficientes en la responsabilidad extracontractual”. (trad.) Arturo Ibáñez León y Alberto Pino Emhart. Revista Chilena de Derecho, vol. 43, n. ${ }^{\circ}$ 3. Santiago.

Infantino, Marta \& Elenim Zervogianni (2017). "The Place and Space of Causation", in Marta Infantino \& Elenim Zervogianni (eds.). Causation in European Tort Law. Cambridge: Cambridge University Press.

Jaramillo Contreras, Marcos (2012). "La regulación jurídica en torno a los desastres en Japón”, en AA.VV. Derecho y catástrofe: lecciones del terremoto. Santiago: Universidad de Chile. Facultad de Derecho, Programa Derecho Piensa en Chile.

Kehsler Molina, Mikaela (2018). Responsabilidad civil derivada de desastres naturales, entre privados. Análisis jurisprudencial. Tesis para optar al grado de Licenciada en Ciencias Jurídicas. Santiago: Universidad Alberto Hurtado, Facultad de Derecho, no publicada.

Lara Arroyo, José Luis y Luis Eugenio García-Huidobro Herrera (2014). “27F: ¿Terremoto en la responsabilidad del Estado?”. Anuario de Doctrina y Jurisprudencia. Sentencias destacadas 2013. Santiago: Ediciones Libertad y Desarrollo.

Larroucau Torres, Jorge (2012). "Hacia un estándar de prueba civil". Revista Chilena de Derecho, vol. 39, n. ${ }^{\circ}$ 3. Santiago.

LARROUCAU TORRES, Jorge (2014). “¿Cómo se prueba la responsabilidad civil médica en la justicia chilena?”. Revista de Derecho (Valdivia), vol. XXVII, n. ${ }^{\circ}$ 2. Valdivia.

Mejías Alonzo, Claudia (2019). "Pérdida de una chance. Una revisión a partir de los requisitos del daño indemnizable”, en Maricruz GómEz de LA TORRE VARGAS et al. (eds.). Estudios de derecho civil XIV. Santiago: Editorial Thomson Reuters.

Mellafe, Rolando (2004). "El acontecer infausto en el carácter chileno: una proposición de historia de las mentalidades", en Rolando Mellafe. Historia social de Chile y América, $4^{\mathrm{a}}$ ed. Santiago: Editorial Universitaria.

Molina, Juan Ignacio (1788). Compendio de la historia geográfica natural y civil del reyno de Chile. Primera parte (trad.) Domingo Joseph DE ArQuellada MenDOZA. Madrid: Antonio de Sancha.

Nivolianitou, Zoe (2002). "Risk analysis and risk management: a European insight". Law, Probability and Risk, No. 1. Oxford. 
Olcina Cantos, Jorge (2006). "La ordenación del territorio en la mitigación de riesgos naturales en España: estudio de casos", en Francisco Javier Ayala CARCEDO et al. (eds.). Riesgos naturales y desarrollo sostenible. Impacto, predicción y mitigación. Madrid: Instituto Geológico y Minero de España.

Onemi (1974). Memoria histórica Oficina Nacional de Emergencia Ministerio del Interior 1974-2004. Disponible en https://web.archive.org/web/20150402135338/ http://repositoriodigitalonemi.cl/web/bitstream/handle/123456789/1647/ MemoriaHistoricaONEMI19742004.pdf?sequence=1 [fecha de consulta: 16 de enero de 2020].

Ríos, Diego Martín (2010). "Urbanización de áreas inundables, mediación técnica y riesgo de desastre: una mirada crítica sobre sus relaciones". Revista de Geografía del Norte Grande, n. ${ }^{\circ}$ 47. Santiago.

Ríos Erazo, Ignacio (2017). Incerteza Causal en la Responsabilidad Civil.Jurisprudencia terremoto del 27 de febrero de 2010. Tesis para optar al grado de Magíster en derecho con mención en Derecho Privado. Santiago: Universidad de Chile. Facultad de Derecho. No publicada.

Ríos Erazo, Ignacio Javier y Rodrigo Pascual Silva GoÑ (2014). Responsabilidad civil por pérdida de la oportunidad. Santiago: Editorial Jurídica de Chile.

Ríos Insua, David, Claudia Ceppi, Karla Melendez y Juan José Molero (2013). "Cambio climático, fenómenos meteorológicos extremos y análisis de riesgos". Revista de la Real Academia de Ciencias Exactas, Físicas y Naturales, vol. 106, n. ${ }^{\circ}$ 1-2. Disponible en https://rac.es/ficheros/doc/01106.pdf [fecha de consulta: 25 de septiembre de 2020].

Romero, Hugo y Claudia Vidal (2014). "Exposición, sensibilidad y resiliencia ante los desastres de las ciudades de Concepción-Talcahuano, Chile Central”, en Catalina Arteaga A. y Hugo Romero A. (eds.). Vulnerabilidades y desastres socionaturales. Santiago: Editorial Universitaria.

SAn Martín Neira, Lilian C. (2011). "A propósito de un caso de culpa por omisión”. Revista de Derecho. Universidad de Concepción, n. o 229-230. Concepción.

SAN MaRTín NeIRA, Lilian C. (2012): La carga del perjudicado de evitar o mitigar el daño. Estudio histórico-comparado. Bogotá: Universidad Externado de Colombia.

San Martín Neira, Lilian C. (2013). "Responsabilidad del Estado por falta de servicio 'Valenzuela Flores y otros con Fisco de Chile' (rol n. $\left.{ }^{\circ} 1629-2013\right)$ ". Roma e América, n. ${ }^{\circ} 34$. Roma.

SAn Martín NeIRA, Lilian C. (2018). La culpa de la víctima en la responsabilidad civil. Santiago: DER Ediciones.

SAn Martín Neira, Lilian C. (2019). "Desastres naturales y responsabilidad civil. Identificación de los desafíos que presenta esta clase de hechos dañinos". Revista de Derecho (Valdivia), vol. XXXII, n. ${ }^{\circ}$ 2. Valdivia.

SAn Martín Neira, Lilian C. (2020). “¿Hacia una función social de la responsabilidad civil?”, en María Elisa Morales y Pamela Mendoza Alonzo (dirs.). Estudios de derecho privado. Santiago: DER Ediciones, en prensa. 
San Martín Neira, Lilian C. y Jorge Larroucau Torres (2020). "El razonamiento probatorio en la causalidad en la responsabilidad civil: los criterios jurídicos en que se funda la jurisprudencia chilena". Revista de Derecho Privado. Universidad Externado de Colombia, n. ${ }^{\circ}$ 40, en prensa.

Santiago-Lastra, José Antonio, Miriam López-Carmona y Sergio LóPez-MendoZA (2008). "Tendencias del cambio climático global y los eventos extremos asociados". Ra Ximhai, vol. 4, n. ${ }^{\circ}$ 1. Disponible en http://uaim.edu.mx/webraximhai/Ej-12articulosPDF/6-Dr\%20Santiago\%20UNICH.pdf [fecha de consulta: 16 de septiembre de 2020].

SANTini, Oscar (2015). Emergencias y desastres. Gestión de riesgos. Estrategias preventivas y rehabilitación psicosocial. Córdoba: Brujas.

Sernageomin (2017). "Principales desastres ocurridos desde 1980 en Chile". Disponible en http://sitiohistorico.sernageomin.cl/pdf/presentaciones-geo/ Primer-Catastro-Nacional-Desastres-Naturales.pdf [fecha de consulta: 30 de septiembre de 2020].

Silva Avaria, Bárbara y Alfredo Riquelme Segovia (2018). Una identidad terremoteada. Comunidad y territorio en el Chile de 1960. Santiago: Ediciones Universidad Alberto Hurtado.

Swiss RE (2019). "Natural catastrophes and man-made disasters in 2018: 'secondary' perils on the frontline". Sigma, n. ${ }^{\circ}$ 2/2019. Disponible en www.swissre. com/dam/jcr:c37eb0e4-c0b9-4a9f-9954-3d0bb4339bfd/sigma2_2019_en.pdf

180 [fecha de consulta: 17 de enero de 2020].

TAPIA R., Mauricio (2019). Caso fortuito o fuerza mayor. $2^{\text {a }}$ ed. Santiago: Editorial Thomson Reuters.

Ugarte, Ana María, Marcela Salgado y Xenia Fuster (2014). "Emergencia de sujeto político y experiencia de acción colectiva en desastres socionaturales: Análisis de casos en Santiago, Constitución y Chaitén, Chile”, en Catalina Arteaga A. y Ricardo Tapia Z. (eds.). Vulnerabilidades y desastres socionaturales. Experiencias recientes en Chile. Santiago: Editorial Universitaria.

VICUÑa, Sebastián (2019). "Introducción al impacto y adaptación al cambio climático", en Juan Carlos Castilla et al. (eds.). Cambio climático en Chile. Ciencia, mitigación y adaptación. Santiago: Ediciones UC.

\section{Normas citadas}

Decreto supremo 1512 del Ministerio del Interior, publicado el 18 de febrero de 2017. Disponible en www.leychile.cl/Navegar?idNorma=1100397 [fecha de consulta: 3 de enero de 2020].

Marco de Acción de Hyogo para 2005-2015. Disponible en www.eird.org/cdmah/ contenido/hyogo-framework-spanish.pdf [fecha de consulta: 10 de diciembre de 2019].

Ley n. ${ }^{\circ} 19525$, de 2017. 


\section{Jurisprudencia citada}

Adil Brkovic Almonte con Inmobiliaria Armas Capital Limitada (2016): Corte Suprema, 13 de julio de 2016, rol n. ${ }^{\circ}$ 7069-2015. Disponible en https://westlawchile.cl [fecha de consulta: 30 de septiembre de 2020].

Alba Oñate Sanhueza con Fisco de Chile (2016): Corte Suprema, 7 de junio de 2016, rol n. ${ }^{\circ}$ 32262-2015. Disponible en https://westlawchile.cl [fecha de consulta: 30 de septiembre de 2020].

Alejandra Sotta Bunster y otros con Sociedad Concesionaria Autopista (2015): Corte Suprema, 12 de enero de 2015, rol n. ${ }^{\circ}$ 24898-2014. Disponible en https:// westlawchile.cl [fecha de consulta: 30 de septiembre de 2020].

Alejandro Moscoso Larenas con Fisco de Chile (2016): Corte Suprema, 4 de octubre de 2016, rol n. ${ }^{\circ}$ 24306-2016. Disponible en https://westlawchile.cl [fecha de consulta: 30 de septiembre de 2020].

Ángel Sepúlveda Sepúlveda con Fisco de Chile (2019): Corte Suprema, 14 de agosto de 2019, rol n. ${ }^{\circ}$ 2456-2018. Disponible en https://westlawchile.cl [fecha de consulta: 30 de septiembre de 2020].

Bárbara Ivanschitz Boudeguer y otros con Constructora Kuden SPA (2018): $2^{\circ} \mathrm{Juz}-$ gado Civil de Talcahuano, 28 de febrero de 2018, rol n. ${ }^{\circ} \mathrm{C}-1598-2017$. Disponible en www.pjud.cl [fecha de consulta: 30 de septiembre de 2020].

Bárbara Ivanschitz Boudeguer y otros con Constructora Kuden SPA (2019): Corte de Apelaciones de Concepción, 18 de abril de 2019, rol n. ${ }^{\circ}$ 574-2018. Disponible en www.pjud.cl [fecha de consulta: 30 de septiembre de 2020].

Carlos Vargas Alvarado con Fisco y otro (2010): Corte Suprema, 18 de octubre de 2010, rol n. ${ }^{\circ}$ 3060-2010. Disponible en https://westlawchile.cl [fecha de consulta: 30 de septiembre de 2020].

Carolina Luna Miranda con Fisco de Chile (2018): Corte Suprema, 26 de marzo de 2018, rol n. ${ }^{\circ}$ 10165-2017. Disponible en https://westlawchile.cl [fecha de consulta: 30 de septiembre de 2020].

Comunidad Edificio Don Roberto con Inmobiliaria e Inversiones Mitras Corp Limitada (2013): Corte Suprema, 30 de octubre de 2013, rol n. ${ }^{\circ} 6674-2013$. Disponible en https://westlawchile.cl [fecha de consulta: 30 de septiembre de 2020].

Corina Solís Palominos y otros con Dirección de Vialidad (2014): Corte Suprema, 7 de enero de 2014, rol n. ${ }^{\circ}$ 9580-2013. Disponible en https://westlawchile.cl [fecha de consulta: 30 de septiembre de 2020].

Corporación Administrativa del Poder Judicial con Conservación y Mantención de Edificios Limitada (2016): Corte Suprema, 4 de enero de 2016, rol n. ${ }^{\circ} 4886-2015$. Disponible en https://westlawchile.cl [fecha de consulta: 30 de septiembre de 2020].

Corporación administrativa del Poder Judicial con Sergio Eduardo Morales Ibarra (2015): Corte Suprema, 11 de agosto de 2015, rol n. ${ }^{\circ} 28625-2014$. Disponible en https://westlawchile.cl [fecha de consulta: 30 de septiembre de 2020].

Cristián Sánchez Díaz y otros con Inmobiliaria Miramar Limitada y otro (2019): Corte Suprema, 23 de julio de 2019, rol n. ${ }^{\circ}$ 1248-2018. Disponible en https:// westlawchile.cl [fecha de consulta: 30 de septiembre de 2020]. 
Diodina Lefiqueo Pincheira con Fisco de Chile (2017): Corte Suprema, 16 de noviembre de 2017, rol n. ${ }^{\circ}$ 4658-2017. Disponible en https://westlawchile.cl [fecha de consulta: 30 de septiembre de 2020].

Elías Cifuentes Sánchez y otros con Fisco de Chile (2017): Corte Suprema, 28 de agosto de 2017, rol n. ${ }^{\circ}$ 97661-2016. Disponible en https://westlawchile.cl [fecha de consulta: 30 de septiembre de 2020].

Elsa Sara Cabezas Paillali con Sociedad Concesionaria Rutas del Pacífico S.A

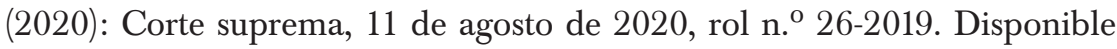
en https://westlawchile.cl [fecha de consulta: 30 de septiembre de 2020].

Emilio Sahurie Luer con Jahuel Ingeniería y Construcción Limitada (2007): Corte Suprema, 11 de septiembre de 2007, rol n. ${ }^{\circ}$ 6212-2005. Disponible en https:// westlawchile.cl [fecha de consulta: 30 de septiembre de 2020].

Enzo Danke de la Harpe y otros con The Conservation Land Trust y otros (2013): Corte Suprema, 12 de junio de 2013, rol n. ${ }^{o}$ 2448-2010. Disponible en https:// westlawchile.cl [fecha de consulta: 30 de septiembre de 2020].

Fabián Bastías Olea y otros con Fisco de Chile y otro (2017): Corte Suprema, 13 de noviembre de 2017, rol n. ${ }^{\circ}$ 6860-2017. Disponible en https://westlawchile. cl [fecha de consulta: 30 de septiembre de 2020].

Fernando Aspillaga Rodríguez con Héctor Sauvageot Torrecilla y otros (2017): Corte Suprema, 21 de agosto de 2017, rol n. ${ }^{\circ}$ 10373-2017. Disponible en https://westlawchile.cl [fecha de consulta: 30 de septiembre de 2020].

Francisca Saravia Núñez con Compañía Siderúrgica Huachipato S.A. (2016): Corte Suprema, 11 de octubre de 2016, rol n. ${ }^{\circ}$ 32434-2014. Disponible en https://westlawchile.cl [fecha de consulta: 30 de septiembre de 2020].

Gabriela Sepúlveda Aliste con Fisco de Chile (2017): Corte Suprema, 12 de diciembre de 2017, rol n. ${ }^{\circ}$ 172-2017. Disponible en https://westlawchile.cl [fecha de consulta: 30 de septiembre de 2020].

Guacolda Carrasco Pérez y otros con Empresa Nacional de Electricidad (2015): Corte Suprema, 22 de junio de 2015, rol n. ${ }^{\circ}$ 23652-2014. Disponible en https://westlawchile.cl [fecha de consulta: 30 de septiembre de 2020].

Guillermo Claverie Bravo y otros con Fisco de Chile (2013): Corte Suprema, 6 de marzo de 2013, rol n. ${ }^{\circ}$ 9074-2011. Disponible en https://westlawchile.cl [fecha de consulta: 30 de septiembre de 2020].

Guillermo Ramón Pérez Freire y otros con Fisco de Chile (2019): Corte Suprema, 1 de febrero de 2019, rol n. ${ }^{\circ}$ 3033-2018. Disponible en https://westlawchile. cl [fecha de consulta: 30 de septiembre de 2020].

Helmar Roland Viertel Molina con Ruta de los Ríos Sociedad Concesionaria S.A. (2019): Corte Suprema, 11 de diciembre de 2019, rol n. ${ }^{\circ}$ 16684-2018. Disponible en https://westlawchile.cl [fecha de consulta: 30 de septiembre de 2020].

Humberto Senerega Puga con I. Municipalidad de Viña del Mar (2007): Corte de Apelaciones de Valparaíso, 24 de septiembre de 2007, rol n. ${ }^{\circ}$ 3346-2003. Disponible en https://westlawchile.cl [fecha de consulta: 30 de septiembre de 2020]. 
Iván Espíndola Canelo y otra con Gloria Arbulo Núñez y otros (2016): Corte Suprema, 4 de septiembre de 2016, rol n. ${ }^{\circ}$ 58924-2016. Disponible en https:// westlawchile.cl [fecha de consulta: 30 de septiembre de 2020].

José Venegas Toro con Municipalidad de Antofagasta (2017): Corte Suprema, 27 de diciembre de 2017, rol n. ${ }^{\circ}$ 34536-2017. Disponible en https://westlawchile.cl [fecha de consulta: 30 de septiembre de 2020].

Juan Soto Morales con Fisco de Chile (2013): Corte Suprema, 23 de enero de 2013, rol $\mathrm{n}^{\mathrm{o}}$ 1250-2012. Disponible en https://westlawchile.cl [fecha de consulta: 30 de septiembre de 2020].

Luis Felipe Baeza Balbontín con Ilustre Municipalidad de Viña del Mar (2005): Corte Suprema, 26 de mayo de 2005, rol n. ${ }^{\circ} 41-2004$. Disponible en https:// westlawchile.cl [fecha de consulta: 30 de septiembre de 2020].

Luis Mella Guzmán y otros con Fisco de Chile (2018): Corte Suprema, 3 de marzo de 2018, rol n. ${ }^{\circ}$ 42539-2017. Disponible en https://westlawchile.cl [fecha de consulta: 30 de septiembre de 2020].

Luis Salgado Delgado y otro con Fisco de Chile (2014): Corte Suprema, 29 de abril de 2014, rol n. ${ }^{\text {O } 16920-2013 . ~ D i s p o n i b l e ~ e n ~ h t t p s: / / w e s t l a w c h i l e . c l ~[f e c h a ~}$ de consulta: 30 de septiembre de 2020].

Luis Vergara Reyes y otros con I. Municipalidad de Concepción (2003): Corte Suprema, 27 de noviembre de 2003, rol n. ${ }^{\circ} 4680-2002$. Disponible en https:// westlawchile.cl [fecha de consulta: 30 de septiembre de 2020].

Luisa Torres Puentes y otro con I. Municipalidad de Talcahuano (2016): Corte Suprema, 14 de junio de 2016, rol n. ${ }^{\circ}$ 16952-2016. Disponible en https:// westlawchile.cl [fecha de consulta: 30 de septiembre de 2020].

Luz Eliana Sandoval Rivera y otros con Muñoz Muñoz José Gabriel y otro (2012): Corte Suprema, 29 de mayo de 2012, rol n. ${ }^{\circ}$ 217-2010. Disponible en https:// westlawchile.cl [fecha de consulta: 30 de septiembre de 2020].

Macarena Schuster Pinto y otros con Fisco de Chile (2020): Corte Suprema, 29 de mayo de 2020, rol n. ${ }^{\circ}$ 5572-2019. Disponible en https://westlawchile.cl [fecha de consulta: 30 de septiembre de 2020].

Manuel Escalona Allendes y otros con Fisco de Chile (2017): Corte Suprema, 9 de noviembre de 2017, rol n. ${ }^{\circ}$ 12169-2017. Disponible en https://westlawchile.cl [fecha de consulta: 30 de septiembre de 2020].

Manuelita Labbé Correa y otro con I. Municipalidad de San Bernardo (2007): Corte de Apelaciones de San Miguel, 8 de noviembre de 2007, rol n. ${ }^{\circ} 1749$ 2005. Disponible en https://westlawchile.cl [fecha de consulta: 30 de septiembre de 2020].

Marco Santander López con Municipalidad de Antofagasta (2017): Corte Suprema, 27 de diciembre de 2017, rol n. ${ }^{\circ}$ 37834-2017. Disponible en https:// westlawchile.cl [fecha de consulta: 30 de septiembre de 2020].

María Angélica Rivera Araneda con Ilustre Municipalidad de La Unión (2001): Corte Suprema, 3 de mayo de 2001, rol n. ${ }^{\circ}$ 3176-2000. Disponible en https:// westlawchile.cl [fecha de consulta: 30 de septiembre de 2020]. 
María Arévalo Fuentealba con Municipalidad de Lebu (2013): Corte Suprema, 2 de enero de 2013, rol n. ${ }^{\circ}$ 9726-2011. Disponible en https://westlawchile.cl [fecha de consulta: 30 de septiembre de 2020].

María del Carmen Valenzuela Flores y otros con Fisco de Chile (2013): Corte Suprema, 18 de diciembre de 2013, rol n. ${ }^{\circ}$ 1629-2013. Disponible en https:// westlawchile.cl [fecha de consulta: 30 de septiembre de 2020].

María Soledad Manríquez Aravena con Fisco De Chile (2008): Corte Suprema, 15 de octubre de 2008, rol n. ${ }^{\circ}$ 3151-2007. Disponible en https://westlawchile.cl [fecha de consulta: 30 de septiembre de 2020].

Mario Quezada Silva y otros con Fisco de Chile (2017): Corte Suprema, 17 de mayo de 2017, rol n. ${ }^{\circ}$ 22185-2016. Disponible en https://westlawchile.cl [fecha de consulta: 30 de septiembre de 2020].

Marioly Gatica Valdebenito y otros con Fisco de Chile (2019): Corte Suprema, 18 de marzo de 2019, rol n. ${ }^{\circ} 4185-2018$. Disponible en https://westlawchile. cl [fecha de consulta: 30 de septiembre de 2020].

Marta Adela Fonseca Vásquez con Fisco de Chile (2014): Corte Suprema, 29 de abril de 2014, rol n. ${ }^{0}$ 16885-2013. Disponible en https://westlawchile.cl [fecha de consulta: 30 de septiembre de 2020].

Marta María Araya Muñoz con I. Municipalidad de Peñaflor (2007): Corte de Apelaciones de San Miguel, 10 de diciembre de 2007, rol n. ${ }^{\circ}$ 1705-2006. Disponible en https://westlawchile.cl [fecha de consulta: 30 de septiembre de 2020].

Norma Silva Hidalgo con Fisco de Chile (2018): Corte Suprema, 4 de diciembre de 2018, rol n. ${ }^{\circ}$ 45305-2017. Disponible en https://westlawchile.cl [fecha de consulta: 30 de septiembre de 2020].

Patricia Soto González y otros con Jahuel Ingeniería y Construcción Limitada y otros (2013): Corte Suprema, 30 de enero de 2013, rol n. ${ }^{\circ}$ 1083-2010. Disponible en https://westlawchile.cl [fecha de consulta: 30 de septiembre de 2020].

Percy Harold Cepeda Martignoni con José Gabriel Alemparte Rojas y otros (2016): Corte Suprema, 21 de diciembre de 2016, rol n. ${ }^{\circ}$ 73871-2016. Disponible en https://westlawchile.cl [fecha de consulta: 30 de septiembre de 2020].

René Pinto Flores y otros con Fisco de Chile (2018): Corte Suprema, 17 de enero de 2018, rol n. ${ }^{\circ}$ 5094-2017. Disponible en https://westlawchile.cl [fecha de consulta: 30 de septiembre de 2020].

Rivera Muñoz Viviana con Fisco de Chile (2019): Corte Suprema, 21 de enero de 2019, Rol No 40166-2017. Disponible en https://westlawchile.cl [fecha de consulta: 30 de septiembre de 2020].

Robinson Green Gómez y otro con Fisco de Chile (2017): Corte Suprema, 31 de julio de 2017, rol n. ${ }^{\circ} 88986-2016$. Disponible en https://westlawchile.cl [fecha de consulta: 30 de septiembre de 2020].

Rodrigo Araya Carreño y otros con Fisco de Chile y otros (2020): Corte Suprema, 19 de mayo de 2020, rol n. ${ }^{\circ}$ 25169-2019 en https://westlawchile.cl [fecha de consulta: 30 de septiembre de 2020]. 
Ronald Pérez Flores con Viviendas 2000 Limitada (2016): Corte Suprema, 30 de diciembre de 2016, rol n. ${ }^{\circ}$ 19724-2015 en https://westlawchile.cl [fecha de consulta: 30 de septiembre de 2020].

Sandra Margoth Vidal y otros con Ruta de los Ríos Sociedad Concesionaria y otro (2013): Corte Suprema, 22 de mayo de 2013, rol n. ${ }^{\circ} 4263-2011$. Disponible en https://westlawchile.cl [fecha de consulta: 30 de septiembre de 2020].

Sergio Eduardo Ortiz Troncoso con Inmobiliaria Don Cristóbal S.A. (2016): Corte Suprema, 10 de marzo de 2016, rol n. ${ }^{\circ}$ 33651-2015. Disponible en https:// westlawchile.cl [fecha de consulta: 30 de septiembre de 2020].

Sociedad Concesionaria Rutas del Pacífico S.A. con Sociedad Agrícola ARC Holding Ltda. y otros (2015): Corte de Apelaciones de Santiago, 27 de febrero de 2015, rol n. ${ }^{\circ}$ 7396-2014. Disponible en https://westlawchile.cl [fecha de consulta: 30 de septiembre de 2020].

Sociedad Pastelería Arraya Limitada con I. Municipalidad de Talcahuano y otro (2016): Corte Suprema, 12 de abril de 2016, rol n. ${ }^{\circ} 37438-2015$. Disponible en https://westlawchile.cl [fecha de consulta: 30 de septiembre de 2020].

Soto González Patricia del Carmen y otros con Jahuel Ingeniería y Construcción Limitada y otros (2007). $20^{\circ}$ Juzgado Civil de Santiago, 20 de diciembre de 2007, rol n. ${ }^{\circ}$ C-2948-2004. Disponible en https://vlex.com/ [fecha de consulta: 30 de septiembre de 2020].

Universidad de Talca con Constructora Marcelo Rivano Limitada (2019): Corte Suprema, 17 de julio de 2019, rol n. ${ }^{\circ}$ 40703-2017. Disponible en https:// westlawchile.cl [fecha de consulta: 30 de septiembre de 2020].

Víctor Arriagada Sepúlveda y otros con Fisco de Chile (2018): Corte Suprema, 17 de abril de 2018, rol n. ${ }^{\circ}$ 18225-2017. Disponible en https://westlawchile.cl [fecha de consulta: 30 de septiembre de 2020].

Vladimir Cáceres Vergara con Inmobiliaria San Pedro del Valle S.A. y otros (2017): Corte Suprema, 25 de enero de 2017, rol n. ${ }^{\circ}$ 24349-2016. Disponible en https://westlawchile.cl [fecha de consulta: 30 de septiembre de 2020].

\section{SigLAS Y ABREVIATURAS}

27F 27 de febrero de 2010

AA.VV. autores varios

ADN ácido desoxirribonucleico

al. alii (otros)

art. artículo

CC Código Civil

CCR Caisse Centrale de Reassurance

Cfr. Confróntese

Cigiden Centro Nacional de Investigación para la Gestión Integrada de Desastres Naturales 
Citrid Programa de Reducción de Riesgos de la Universidad de Chile

CONAF Corporación Nacional Forestal

Corfo Corporación de Fomento de la Producción

DGA Dirección General de Aguas

dirs. directoras

DS decreto supremo

ed. edición

eds. editores

Endesa Empresa Nacional de Electricidad

EQC Earthquake Commission

etc. etcétera

Fondecyt Fondo Nacional de Desarrollo Científico y Tecnológico

http Hypertext Transfer Protocol

https Hypertext Transfer Protocol Secure

I. Ilustre

JERC Japan Earthquake Reinsurance Co. Ltd.

MAH Marco Acción de Hyogo

Minvu Ministerio de Vivienda y Urbanismo

mm milímetros

MOP Ministerio de Obras Públicas

n. ${ }^{\circ}$ a veces $\mathrm{N}^{\mathrm{o}}$, No. número

Onemi Oficina Nacional de Emergencia

ONU Organización de las Naciones Unidas

p. página

pp. páginas

trad. traducción

SD Sin data

Sernageomin Servicio Nacional de Geología y Minería

Serviu Servicio Vivienda y Urbanismo

UC Universidad Católica

UK United Kingdom

UNISDR United Nations Office for Disaster Risk Reduction

v. gr. verbi gratia

vol. volumen 